Universidade de São Paulo

Faculdade de Odontologia

Carmen Victoria Torres Toro

\title{
Eficiência na remoção de tecido desmineralizado com laser Er:YAG e sua influência na permeabilidade da dentina
}

Ribeirão Preto 2011 


\section{CARMEN VICTORIA TORRES TORO}

\section{Eficiência na remoção de tecido \\ desmineralizado com laser Er:YAG e sua \\ influência na permeabilidade da \\ dentina}

Dissertação apresentada na Faculdade de

Odontologia de Ribeirão Preto da

Universidade de São Paulo para a

obtenção do título de Mestre em

Odontologia

Área de Concentração: Dentística

Orientadora: Profa. Dra. Regina Guenka Palma Dibb

Ribeirão Preto 
Autorizo a reprodução e divulgação total ou parcial deste trabalho, por qualquer meio convencional ou eletrônico, para fins de estudo e pesquisa, desde que citada a fonte.

Assinatura do autor:

Data:

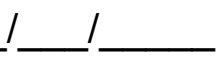

Eficiência na remoção de tecido desmineralizado com laser Er:YAG e sua influência na permeabilidade da dentina

Ficha catalográfica preparada pela Seção de Tratamento da Informação do Serviço de Biblioteca - EESC-USP

Toro, Carmen Victoria Torres

Eficiência na remoção de tecido desmineralizado com laser Er:YAG e sua influência na permeabilidade da dentina / Carmen Victoria Torres Toro; orientadora Regina Guenka Palma Dibb. - Ribeirão Preto, 2011.

64p. :il.: $30 \mathrm{~cm}$

Dissertação de mestrado apresentado na Faculdade de Odontologia de Ribeirão Preto da Universidade de São Paulo. Departamento de Odontologia Restauradora - Área de concentração: Dentística.

1. Laser Er:YAG. 2. Caries dental. 3. Dentina. 4. Permeabilidade dentinária.

5. Cavidade dentária. 
Nome: Toro, Carmen Victoria Torres.

Título: Eficiência na remoção de tecido desmineralizado com laser Er:YAG e sua influência na permeabilidade da dentina

Dissertação apresentada à Faculdade de Odontologia de Ribeirão Preto da Universidade de São Paulo, para a

Aprovado em: obtenção do título de Mestre em Dentística.

Banca Examinadora

$\operatorname{Prof}(a) \cdot \operatorname{Dr}(a)$.

Instituição:

Julgamento:

Assinatura:

Prof(a). Dr(a).

Instituição:

Julgamento:

Assinatura:

Prof(a). Dr(a).

Instituição:

Julgamento:

Assinatura: 


\section{Dedicatória}

\section{A Deus}

Por seu amor, guia e proteção, sustentado-me nas provas desta vida para que eu consiga seguir o caminho de luz.

\section{A minha máe, Maria Del Carmen}

Minha querida mãe, sempre me apoiando e incentivando ao longo da minha caminhada. Sendo essencial na minha vida seu amor incondicional e confiança.

\section{Ao meu pai, Javier}

Pelo seu apoio, carinho e amor nos momentos da minha vida, permitindo-me seguir minhas metas.

\section{A minha irmã, Cristima}

Minha melhor amiga, que sempre me ofereceu seu carinho e apoio.

\section{Ao meu noivo, Janimar}

Agradeço seu apoio e amor, importantes na minha vida.

\section{Aos meus tios, Cristina e Juan Carlos}

Sempre me estiveram apoiando e auxiliando quando precisei, agradeço seu amor e carinho.

\section{Aos meus primos, Juan Carlos, Daola, Arturo, Marcelo, Alejandro e Alioth}

Pelo apoio e incentivo, estando sempre presentes nos momentos importantes. 


\section{Agradecimentos Especiais}

Agradeço a Deus por me dar a vida e uma linda família, agradeço por me guiar em minhas escolhas e me mostrar o caminho certo.

À minha Família que sempre está presente, me dando segurança para enfrentar os desafios e as dificuldades.

À Profa. Dra. Regina Guenka Palma Dibb, agradeço sua orientação, sua paciência, amizade e ensinamentos. Sempre me inspirando com bons exemplos de competência, honestidade e ética, contribuindo para o meu crescimento profissional e pessoal.

Á Juliana, agradeço sua amizade e grande apoio em cada momento. 


\section{Agradecimentos}

À Faculdade de Odontologia de Ribeirão Preto da Universidade de São Paulo, através de seu diretor Prof. Dr. Osvaldo Luiz Bezzon.

À Coordenação do Curso de Pós-Graduação em Odontologia Restauradora da Faculdade de Odontologia de Ribeirão Preto/USP, na pessoa do Prof. Dr. Manoel Damião de Souza Neto, que desempenha seu papel com sucesso e dedicação.

Ao vice-coordenador do Curso de Pós-Graduação em Odontologia Restauradora da Faculdade de Odontologia de Ribeirão Preto/USP, Prof. Dr. Marcelo Oliveira Mazetto.

Ao Prof. Dr. Jesus Djalma Pécora, por permitir a utilização do laser Er:YAG do Departamento de Odontologia Restauradora da Faculdade de Odontologia de Ribeirão Preto/USP.

Ao técnico Reginaldo Santana da Silva, por auxiliar na execução dos procedimentos com o laser Er:YAG.

À Dra. Juliana Jendiroba Faraoni Romano, por seu apoio no meu projeto de pesquisa e também por sua amizade.

À técnica do laboratório de Dentística do Departamento de Odontologia Restauradora da Faculdade de Odontologia de Ribeirão Preto/USP Patrícia Marchi, por seu auxilio durante a realização de trabalhos e sua amizade.

À instituição de fomento CNPq, pela bolsa de mestrado. 
Às minhas amigas Kelly, Sandra, Danielle, Taísa e Renata, por sua amizade.

Aos Funcionários do Departamento de Odontologia Restauradora e aos Funcionários da Seção de Pós-Graduação da Faculdade de Odontologia de Ribeirão Preto/USP, que de alguma forma de auxiliaram durante a minha caminhada. 


\section{Resumo}

Toro, CVT. Eficiência na remoção de tecido desmineralizado com laser Er:YAG e sua influência na permeabilidade da dentina [Dissertação]. Ribeirão Preto: Universidade de São Paulo, Faculdade de Odontologia de Ribeirão Preto, 2011. 64f.

O objetivo deste estudo foi avaliar a influência do laser Er:YAG na remoção de dentina desmineralizada e sua permeabilidade no tecido remanescente. 30 fragmentos de dentina coronária a partir de 30 molares foram isolados com esmalte cosmético e cera, deixando uma área exposta de dentina de $9 \mathrm{~mm}^{2}$. Para a obtenção das lesões de cárie os espécimes foram imersos durante 20 dias em solução desmineralizante $\left(\mathrm{pH} 4,6\right.$ a $\left.37^{\circ} \mathrm{C}\right)$. Depois, os corpos de prova foram aleatoriamente divididos em 3 grupos $(n=10)$ para a remoção da lesão: $G 1$ - laser Er:YAG, (200 $\mathrm{mJ} / 6 \mathrm{~Hz}$ ); $\mathrm{G} 2$ - broca; G3 - cureta. Em seguida, os espécimes foram imersos em uma solução aquosa de sulfato de $\mathrm{Cu}$ a $10 \%$ e em uma solução alcoólica de ácido rubiânico a $1 \%$ por 30 minutos, e mantidos em recipientes fechados com bolinha de algodão embebida com amônia por 7 dias. Posteriormente, foram seccionados, polidos, desidratados, clareados e colocados em laminas de vidro para sua analise por meio de microscópio ótico. As medidas de penetração do íon de cobre na dentina remanescente foram medidas $\mathrm{em} \mu \mathrm{m}$. Os dados foram analisados pelo teste Kruskal-Wallis e correlação de Pearson. Pode-se observar que o laser promoveu um

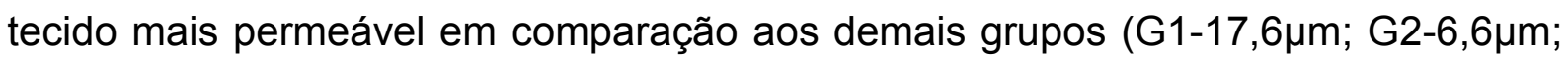
G3-5,5 $\mu \mathrm{m}$ ), contudo não houve diferença estatística entre eles na capacidade de remoção do tecido desmineralizado (G1-10,6 $\mu \mathrm{m} ; \mathrm{G} 2-8,4 \mu \mathrm{m} ; \mathrm{G} 3-11 \mu \mathrm{m})$. A correlação entre a dentina remanescente desmineralizada e permeabilidade dentinária, foi moderada para os metodos convencionais e alta para o laser Er:YAG. Conclui-se que o laser Er:YAG promoveu maior permeabilidade da dentina, estando correlacionada com a remoção do tecido desmineralizado.

Palavras-chave: Laser Er:YAG. Caries dental. Dentina. Permeabilidade dentinária. Cavidade dentaria. 


\begin{abstract}
Toro, CVT. Influence of Er:YAG laser in removing demineralized substrate and dentin permeability [thesis]. Ribeirão Preto: Universidade de São Paulo, Faculdade de Odontologia de Ribeirão Preto, 2011. 64f.

The aim of this study was to evaluate the efficiency of Er:YAG laser in the removing of demineralized dentin and permeability of the remaining dentin. 30 dentin fragments obtained from 30 molars were isolated with enamel cosmetic and wax, leaving a dentin exposed area of $9 \mathrm{~mm}^{2}$, which was submitted to demineralization. For obtaining the lesions, the specimens were immersed during 20 days in a demineralized solution $\left(\mathrm{pH} 4.6\right.$ at $\left.37^{\circ} \mathrm{C}\right)$. The samples were randomly divided into 3 groups $(n=10)$ for the removal of the demineralized lesion: G1- Er:YAG laser, $(200 \mathrm{~mJ} / 6 \mathrm{~Hz})$; G2- bur; G3- curette. Later, the specimens were immersed in $10 \%$ aqueous solution of copper sulfate and $1 \%$ alcoholic solution of rubeanic acid for 30 minutes and it kept in closed jars with ammonium-embedded cotton pellets for 7 days. Then, they were sectioned, polished, dehydrated, cleared and mounted on glass slides for examination under optical microscopy. The percentages of copper ion infiltration in dentin were quantified in $\mu \mathrm{m}$. Data were analyzed by Kruskal-Wallis test and Pearson's correlation. The analyze revealed that the laser promoted more

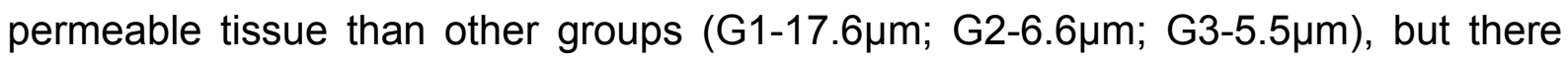
was no statistical difference between them in terms of their capacity of removing the

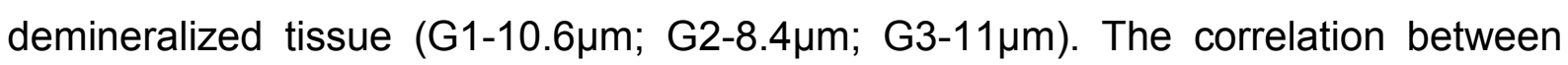
remaining demineralized dentin and dentin permeability was moderated for the conventional methods and high for the Er:YAG laser. It can be concluded by the present study that he Er:YAG laser promoted higher dentin permeability, being correlated with the removal of the demineralized dentin.
\end{abstract}

Keywords: Er:YAG laser. Dental caries. Dentin. Dentin permeability. Dental Cavity Preparation. 


\section{Lista de Figuras}

Figura 1 Representação esquemática da confecção dos espécimes.

Figura 2 Representação esquemática de formação de cárie artificial Máquina de corte.......................................... $\quad 34$

Figura 3 Representação esquemática dos preparos cavitários..

Figura 4 Representação esquemática do teste de permeabilidade Microdurômetro................................... 36

Figura 5 Imagens obtidas através da microscopia de luz com aumento de 40 vezes.................................................. 37

Figura 6 Box plot dos grupos estudados, com relação à permeabilidade da dentina remanescente................... 40

Figura 7 Box plot dos grupos estudados, com relação ao remanescente dentinario desmineralizado....................

Figura 8 Preparo cavitário com laser Er:YAG: Vista superior e vista longitudinal

Figura 9 Preparo cavitário com Broca: Vista longitudinal e superior

Figura 10 Preparo cavitário com Cureta: Vista superior e longitudinal. 


\section{Lista de Tabelas}

Tabela 1 - Mediana, media e desvio padrão em $\mu \mathrm{m}$ da permeabilidade da dentina remanescente.

Tabela 2 - Mediana, média e desvio padrão em $\mu \mathrm{m}$ do remanescente dentinario desmineralizados estudados. 


\section{Lista de Abreviaturas, Siglas e Símbolos}

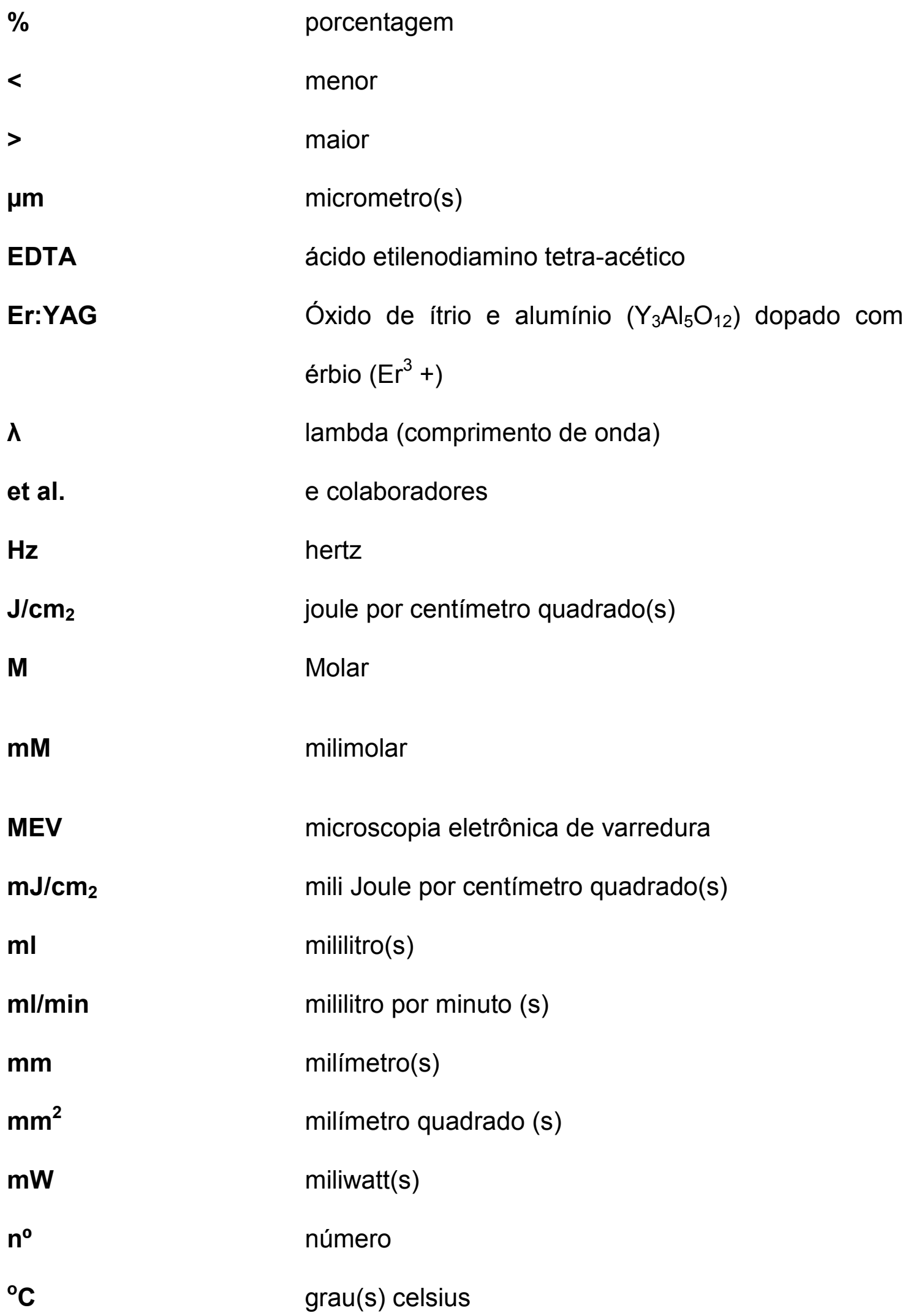


$\mathbf{P}$

$\mathrm{pH}$

ppm

$\mathbf{r}$

$\mathrm{OH}$ fosfato

logaritmo negativo de concentração hidrogeniônica $\left(-\log \left[\mathrm{H}^{+}\right]\right.$

Parte por milhão

Coeficiente de correlação de Pearson

Hidroxila ou hidróxido 


\section{Sumário}

1. Introdução

2. Droposição

3. Material e Método

3.1. Aspectos éticos.

3.2. Delineamento experimental.

3.3. Seleção dos dentes.

3.4. Preparo dos espécimes.

3.5. Formação de cárie artificial.

3.6. Preparos cavitários

3.7. Testes de permeabilidade e Microscopia óptica de luz.

3.8. Microscopia eletrônica de varredura.

3.9. Análise dos dados.

4.1. Permeabilidade dentinária

4.2. Remanescente de dentina desmineralizada. 
5. DiscusSสี

6. Conclusẫ|

Referências Bỉblioqráficas............................................................. 54

AneXOS.................................................................................. 62 
1 Introdução 


\section{Introdução}

Há décadas a cárie dentária tem sido considerada um problema global que pode resultar na destruição e perda dos dentes. A cárie é uma doença infectocontagiosa, resultado de um processo dinâmico, que ocorre através do biofilme formado na superfície dental (Pitss, 2004). Os microrganismos do biofilme realizam a metabolização dos açucares, provenientes da dieta, dando como resultado a produção de ácidos, o qual promove uma flutuação de $\mathrm{pH}$, cujas conseqüências podem ser observadas em níveis químicos e/ou ultraestruturais (subclínicos), até que a perda constante do mineral com a dissolução dos tecidos dentais resultando em uma lesão clinicamente visível (Kidd; Fejerskov, 2004; Pitss, 2004).

Após a perda irreversível da estrutura dentária pelo processo carioso a dentística operatória se apresenta com um papel importante para o controle da evolução da lesão, sendo capaz restabelecer a integridade da estrutura dental através de preparos cavitários e restaurações, permitindo aos pacientes condições para controlar a doença cárie através de uma higienização eficiente.

Os procedimentos seguidos para a confecção do preparo cavitário foram primeiramente idealizados por Black em 1908, com características específicas para as necessidades de retenção dos materiais disponíveis na época, como a amálgama, sem considerar o desenvolvimento da cárie e sua interação com os tecidos (Mount, 2007).

Depois, com o avanço da compreensão do desenvolvimento da cárie e evolução dos materiais restauradores surgiu uma nova Odontologia minimamente invasiva, com uma filosofia voltada à prevenção da carie e conservação da estrutura dentária (Jacobsen; Robinson, 1980, Chalmers, 2006; Murdoch-Kinch; McLean, 2003). 
Um dos achados importantes que começou este período foi a compreensão do desenvolvimento da doença cárie, chegando-se a observar dois tipos de camadas (interna e externa) na dentina cariada (Kubori, et al., 1977). Caracterizando-se a camada mais externa ou dentina infectada por ser macia, apresentando uma contaminação de bactérias e uma matriz colágena necrótica, desorganizada, não passível de remineralização, uma vez que a estrutura de colágeno se encontra desnaturada irreversivelmente. Por outro lado, a camada interna ou dentina afetada, foi diferenciada por apresentar pouca ou nenhuma contaminação bacteriana, uma matriz colágena com sua ultraestrutura original, presença de cristais de hidroxipatita passíveis de remineralização e processos odontoblásticos como na dentina sadia (Ten Cate, 2001). Estes dados permitiram priorizar na Odontologia a remoção seletiva da camada de dentina infectada pelo processo carioso (Kidd, 2004).

Acompanhando esta etapa, os materiais dentários também foram evoluindo, permitindo o surgimento dos materiais adesivos com grandes vantagens na restauração dentaria, entre estas sua característica de poder ser utilizado em preparos cavitários ultraconservadores.

Por outro lado, com relação aos métodos utilizados para a remoção de tecido cariado e preparo cavitário, pode-se verificar que desde há muitos anos vêm sendo empregados com eficiência os instrumentos cortantes manuais como curetas ou instrumentos cortantes rotatórios com brocas adaptadas em turbinas de baixa e alta rotação. Contudo estes métodos apresentam algumas desvantagens, principalmente os instrumentos rotatórios, pois podem gerar desconforto, dor e estresse ao paciente, devido à vibração, pressão, ruído, sendo necessário em muitos casos o uso de anestésicos, também este método exige a habilidade técnica do profissional para que não ocorram desgastes excessivos na estrutura dental, visto que não se tem o controle sobre o tipo de tecido a ser excisado. (Banerjee et al., 2000)

As curetas por sua vez proporcionam a remoção do tecido cariado sem causar calor e vibração, realizando a remoção específica do tecido e minimiza o uso de anestésicos, entretanto a fadiga manual do operador em longos períodos de trabalho (Frencken et al., 1996), o maior tempo demandado para execução do 
procedimento (Banerjee et al., 2000) e a falta de controle na remoção total do tecido contaminado (Frencken et al., 1998; Smales et al., 1999), foram consideradas grandes desvantagens.

Porém, foi encontrado em vários estudos que estes métodos de preparo influenciaram nas propriedades da dentina remanescente, principalmente na permeabilidade. Segundo alguns autores (Pashley, 1984; Tao et al., 1988) o preparo cavitário por meio de instrumentos manuais ou rotatórios resulta na formação da smear layer, cuja composição assemelha-se a do tecido dental e, conseqüentemente, pode conter microrganismos, restos celulares e contaminantes diversos, permanecendo agregada ás paredes cavitárias e á entrada dos túbulos dentinarios (smear plug) o qual atua como uma barreira biológica natural que reduze a permeabilidade da dentina exposta em até 86\% (Pashley et al., 1978), sendo desta maneira necessário o condicionamento acido, para a exposição de dentina intertubular e peritubular, evitando-se prejudicar a interação dos sistemas adesivos com o substrato dental, (Pashley, 1991; Swift et al., 1995).

Porém, novas tecnologias, entre essas o laser, estão sendo pesquisadas para seu emprego na dentística operatória, com o objetivo de melhorar os métodos tradicionais de remoção da carie e realização de preparos cavitários, reduzindo o desconforto do paciente, minimizando o desgaste da estrutura dental sadia e potenciais efeitos deletérios ao tecido pulpar, proporcionando uma superfície mais adequada para a adesão dos materiais restauradores (Parker et al., 2007).

Entre os sistemas de lasers atualmente disponíveis tem-se o laser Érbio: ítrioalumínio-granada (Er:YAG), o qual se apresenta efetivo para a confecção do preparo cavitário (Bertrand et al., 2006), tratamento da superfície do dente (Aranha et al., 2007; Visuri et al., 1996), remoção de materiais restauradores (Correa-Afonso et al., 2008; Lizarelli, 2003), e remoção da carie (Eberhard et al., 2005). Este equipamento também apresenta a vantagem de ser mais confortável para o paciente (Takamori et al., 2003) e em muitos casos pode eliminar a necessidade de anestesia (Chaiyavej et al., 2000).

No entanto, os parâmetros mais adequados do laser para uma remoção seletiva da carie, ainda vêm sendo estudados, sendo poucos estudos que 
comparam a eficiência da seletividade da remoção da lesão cariada entre os diferentes métodos de remoção de cárie.

Por outro lado não existem muitos estudos sobre as propriedades dos tecidos irradiado com o laser Er:YAG, os quais poderiam permitir um melhor conhecimento do laser, melhorando de este modo a eficiência do laser durante a remoção de dentina cariada sem afetar a microestrutura do substrato. 
2 Droposiçãa 


\section{Droposição}

O objetivo deste estudo in vitro foi avaliar à eficiência de remoção de tecido dentinário desmineralizado com laser Er:YAG e sua influência na permeabilidade da dentina. 
3 Material e Método 


\section{Material e Método}

3.1 Aspectos éticos

O presente estudo foi desenvolvido após ser submetido e aprovado pelo Comitê de Ética em Pesquisa da Faculdade de Odontologia de Ribeirão Preto - USP (Processo $n^{\circ}$ 2009.1.338.58.3).

\subsection{Delinhamento experimental}

No presente trabalho in vitro o fator em estudo foi o método de remoção de tecido cariado em 3 níveis (laser Er:YAG, baixa rotação e cureta).

A amostra do experimento foi de 30 espécimes divididos aleatoriamente em 3 grupos $(n=10)$. O estudo foi realizado obedecendo a um delineamento em blocos completos casualizados. As variáveis de resposta quantitativa foram a permeabilidade do tecido e a quantidade de remanescente de dentina desmineralizada após a remoção da carie, através de análise em microscopia óptica de luz e a variável de resposta qualitativa foi análise morfológica da superfície e subsuperfície em microscópio eletrônico de varredura. 
3.3 Seleção dos dentes

Foram selecionados 30 molares humanos hígidos provenientes do banco de dentes da Faculdade de Odontologia de Ribeirão Preto - USP. Os dentes foram limpos com curetas periodontais e escovas de Robinson, nas quais foram colocadas pasta de pedra pomes e água. A desinfecção dos dentes foi realizada com solução de formol 10\% ( $\mathrm{pH} 7,0$ ), preparada com tampão fosfato, na qual ficaram imersos durante uma semana (Dominici et al., 2001), após esse período os dentes foram lavados abundantemente em água corrente, e então armazenados em água deionizada a $4^{\circ} \mathrm{C}$ durante toda a etapa de preparação dos espécimes.

\subsection{Preparo dos espécimes}

Primeiramente, os dentes foram fixados com cera escultura (Asfer Indústria Química Ltda., São Caetano do Sul - SP, Brasil) em uma placa de acrílico para ser levados posteriormente a uma maquina de corte de precisão (Minitom, Struers A/S, Copenhagen, DK-2610, Denmark), que através de um disco diamantado (\#7015, KG Sorensen, Barueri, 06454-920, Brasil), sob refrigeração de água, separou a coroa e a raiz, mediante uma secção de $2 \mathrm{~mm}$ abaixo da junção amelo-cementária.

A seguir as coroas foram individualmente fixadas com cera escultura (Asfer Indústria Química Ltda., São Caetano do Sul - SP, Brasil) em uma placa cilíndrica de acrílico e foram levadas a uma Politriz Arotec APL-4 (Arotec S/A Ind. e Comércio, São Paulo/SP, Brasil) para exposição da dentina, empregando-se lixas d'água (Noton Abrasivos Ltda, São Paulo/SP, Brasil) com granulação de n²80 a n¹200, sendo aplicadas em ordem decrescente de abrasividade, sob refrigeração constante. 
O esmalte superficial de todos os espécimes foi removido até a exposição da dentina abaixo da junção amelodentinária e a porção radicular também foi lixada para a regularização do espécime. Os espécimes foram identificados e armazenados separadamente em recipiente com água deionizada a $4^{\circ} \mathrm{C}$ por um período de 24 horas com o objetivo de reumidificar o substrato dental.

Decorrido este período, realizou-se a delimitação da área de indução de carie, para isso foi colocado uma fita isolante com as dimensões de $3 \mathrm{~mm} \times 3 \mathrm{~mm}\left(9 \mathrm{~mm}^{2}\right)$ na região central da superfície oclusal dos espécimes. Após deste procedimento, foram colocadas duas camadas de esmalte cosmético (Colorama, Procosa Produtos de Beleza Ltda, São Paulo/SP, Brasil) e cera utilidade (Cera Rosa 7, Polidental Industria e Comércio Ltda., São Paulo/SP, Brasil) nas superfícies dos espécimes, deixando somente exposta uma área de dentina de $9 \mathrm{~mm}^{2}$ na superficie oclusal. (Figura 1)

\subsection{Formação de cárie artificial}

Cada amostra foi fixada com cera utilidade (Cera Rosa 7, Polidental Industria e Comércio Ltda., São Paulo/SP, Brasil) no fundo de recipientes individuais, os quais continham $10 \mathrm{~mL}$ de uma solução desmineralizante composta por hidróxido de cálcio $2 \mathrm{mM}$, ácido ortofosfórico $2 \mathrm{mM}$, ácido acético $50 \mathrm{mM}$ e fluoreto de sódio $0,1 \mathrm{ppm}$, com um $\mathrm{pH}$ de 4,2. As amostras foram mantidas na solução desmineralizante e colocadas em estufa a $37^{\circ} \mathrm{C}$ (ECB 1.3 Digital, Odontobrás Ind. e Com. Equip. Med. Odontol. Ltda, Ribeirão Preto/SP, Brasil) por um período de 20 dias, sendo a solução trocada diariamente.

No final desta etapa foi observado nos espécimes uma dentina desmineralizada, simulando o tecido cariado, de acordo com o protocolo modificado por Ceballos e colaboradores (2001) (Figura 2) 
3.6 Preparos cavitários

Após este período os espécimes foram aleatoriamente divididos em três grupos $(n=10)$, para a remoção do tecido desmineralizado.

* Grupo 1: Remoção da lesão com o laser Er:YAG (Kavo Key Laser II, Kavo Co., Biberach - Alemanha) de alta densidade de potência,

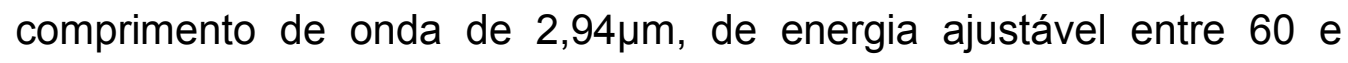

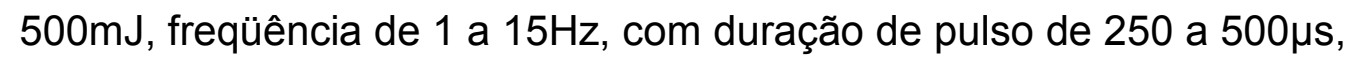
considerando-se uma distância focal ideal de 12,0 mm entre a lente de saída do feixe e o tecido alvo. Por apresentar comprimento de onda localizado na região do infravermelho do espectro eletromagnético, um laser diodo $(\lambda=635 \mathrm{~nm}$; potência $=1 \mathrm{~mW})$ foi usado como feixe guia, com um diâmetro de $0,63 \mathrm{~mm}$.

O laser foi empregado com energia de $200 \mathrm{~mJ}$, taxa de repetição de $6 \mathrm{~Hz}$, saída de água de $4 \mathrm{ml} / \mathrm{min}$, em modo focado e não-contato, a uma distancia de $12 \mathrm{~mm}$ entre a fonte do laser e o espécime. Por outro lado, a densidade de energia do laser foi de $22,21 \mathrm{~J} / \mathrm{cm}^{2}$.

Para a padronização da distancia de irradiação entre o laser e o fragmento, foi utilizado de um dispositivo como suporte, que permitiu regular a distancias entre o espécime e os movimentos da peça de mão do laser.

A presença da lesão na dentina foi distinguida através do som emitido durante as microexplosões (Hibst R, 2002) e a avaliação clinica do operador. Desta maneira o tempo de exposição dos espécimes ao laser foi variado.

Grupo 2: Remoção da lesão por meio de instrumento rotatório de baixa rotação com broca carbide $n^{\circ} 3$ (KG Sorensen, São Paulo/SP, Brasil), 
foi realizada por um único operador que empregou o método visual e táctil para determinar a remoção do tecido amolecido.

* Grupo 3: Remoção da lesão com cureta nº 3 (Duflex, São Paulo/SP, Brasil), foi realizada por um único operador que empregou o método visual e táctil para determinar a remoção do tecido amolecido.

Os espécimes foram identificados e individualmente armazenados em recipientes de plástico com água deionizada (Figura 3)

3.7 Testes de permeabilidade e Microscopia óptica de luz

Após a remoção do tecido desmineralizado, os espécimes foram imersos em solução de sulfato de cobre 10\% (Merck, Darmstadt, Alemanha) e posteriormente em ácido rubiânico 1\% (Merck, Darmstadt, Alemanha), ambos em um período 30 minutos, sendo que nos primeiros 5 minutos a imersão foi realizada sob vácuo. Depois, os corpos de prova foram submetidos ao vapor de amônia por um período de sete dias (Figura 4).

Apos esta etapa, os espécimes foram incluídos em blocos de resina acrílica e seccionados longitudinalmente com uma espessura de $0,5 \mathrm{~mm}$, utilizando um disco diamantado ( $\mathrm{n}^{\circ}$ 7015, KG Sorensen, Barueri, 06454-920, Brasil) montado em máquina de corte (Minitom, Struers A/S, Copenhagen, DK-2610, Denmark), sob refrigeração de água. Posteriormente, os fragmentos foram polidos através do uso manual de lixas d'água (Norton Abrasivos Ltda, São Paulo/SP, Brasil) com granulação de $n^{\circ} 600$ e $n^{\circ} 1200$, até chegar a uma espessura entre $150 \mu m$. Imediatamente, se procedeu à lavagem e remoção de resíduos, para o qual, os fragmentos ficaram imersos em água deionizada sob ação do ultra-som (Ultrasonic Cleaner T - 1449 - D, Odontobrás Indústria e Comércio, Ribeirão Preto - SP, Brasil) 
por 30 minutos. Depois desta etapa, os espécimes foram desidratados em álcool (Labsynth Ltda., Diadema, SP, Brasil) nas concentrações de 70, 80, 96 e 100\%, por um período de duas horas em cada solução e clarificados em xilol em um período de 6 horas. Foi obtido cerca de 2 secções por espécime, as quais foram montadas em lâminas e levadas a um microscópio óptico (Axiostar Plus, Carl Zeiss, Alemanha) com aumento de 40 vezes. No microscópio foi acoplada uma câmera fotográfica digital (Sony Cyber-shot DSC-S75, Japão), que permitiu capturar e digitalizar as imagens (Figura 5), as quais foram analisadas e com o auxilio do software Axion Vision® LE 4.3 (Carl Zeiss, Alemanha) foram obtidas as medidas (em $\mu \mathrm{m}$ ) da dentina remanescente desmineralizada e da profundidade de penetração do corante (Pécora et al., 1990 modificado)

3.8 Microscopia eletrônica de varredura

Para esta analise, se realizou a seleção aleatória de 3 fragmentos por cada grupo, estes foram lavados abundantemente, secos com papel absorvente e, com o auxilio de um paralelômetro, fixados com cera fundida em uma matriz de resina e então levados para o polimento de sua subsuperfície. Este procedimento foi realizado em uma Politriz com lixas d'água (Norton Abrasivos Ltda, São Paulo/SP, Brasil) com granulação de \#600, 1000, 1200 e disco de feltro (Arotec S/A Ind. e Comércio, São Paulo/SP, Brasil) com uma suspensão de alumina 0,3 e 0,05 $\mu \mathrm{m}$ (Arotec S/A Ind. e Comércio, São Paulo/SP, Brasil).

Os fragmentos foram preparados de acordo com o seguinte protocolo:

* Imersão em solução de glutaraldeido a 2,5\% tamponado com solução de cacodilato de sódio por 12 horas a 0,1M com pH 7,4 (Merck KGaA, Darmstadt, D-64293, Alemanha) em temperatura de $4^{\circ} \mathrm{C}$;

* imersão em água destilada;

* aplicação de gel de EDTA por 30 segundos; 
lavagem abundante com spray ar/água destilada;

* limpeza em ultra-som (Ultrasonic Cleaner T - 1449 - D, Odontobrás Indústria e Comércio, Ribeirão Preto - SP, Brasil) em 2 ciclos de 5 minutos em água deionizada, sendo os espécimes lavados em água deionizada entre os dois ciclos ;

* secagem com papel absorvente;

* desidratação dos espécimes através da embebição dos mesmos em diferentes concentrações de etanol (Labsynth Ltda., Diadema, SP, Brasil) por um período pré-determinado (25\% por 20 minutos, $50 \%$ por 20 minutos, $75 \%$ por 20 minutos, $90 \%$ por 30 minutos e $100 \%$ por 1 hora);

* imersão em solução de HMDS (Merck KGaA, Darmstadt, D-64293, Alemanha).

* secagem com papel absorente;

* os espécimes foram fixados em stubs com fita adesiva de carbono dupla-face (Electron Microscopy Sciences, Washington, EUA);

* nos corpos de prova foi realizada a cobertura com ouro em aparelho de metalização a vácuo (SDC 050, Bal-Tec AG, FL9496, Balzers, Liechtenstein)

Os espécimes foram levados ao microscópio eletrônico de varredura (Philips XL30 FEG, Eindhoven, Holanda) pertencente ao Laboratório Multi-Usuários do Departamento de Engenharia de Materiais da Universidade Federal de São Carlos. Foi realizada a varredura de toda a superfície e subsuperfície do espécime e, em seguida, foi fotografada a área mais representativa de cada grupo em diferentes aumentos $(50,500,1000$ e 2000 vezes) 


\subsection{Análise dos dados}

Os dados foram analisados previamente quanto a sua distribuição, como não foi normal optou-se para o emprego do teste de Kruskal-Wallis para o remanescente de tecido desmineralizado e permeabilidade e posteriormente realizou-se a correlação de Pearson para determinar a correlação entre a permeabilidade e remanescente dentinario.

Para a variável de resposta qualitativa (MEV e microscopia óptica de luz) foi realizada uma análise descritiva dos achados. 


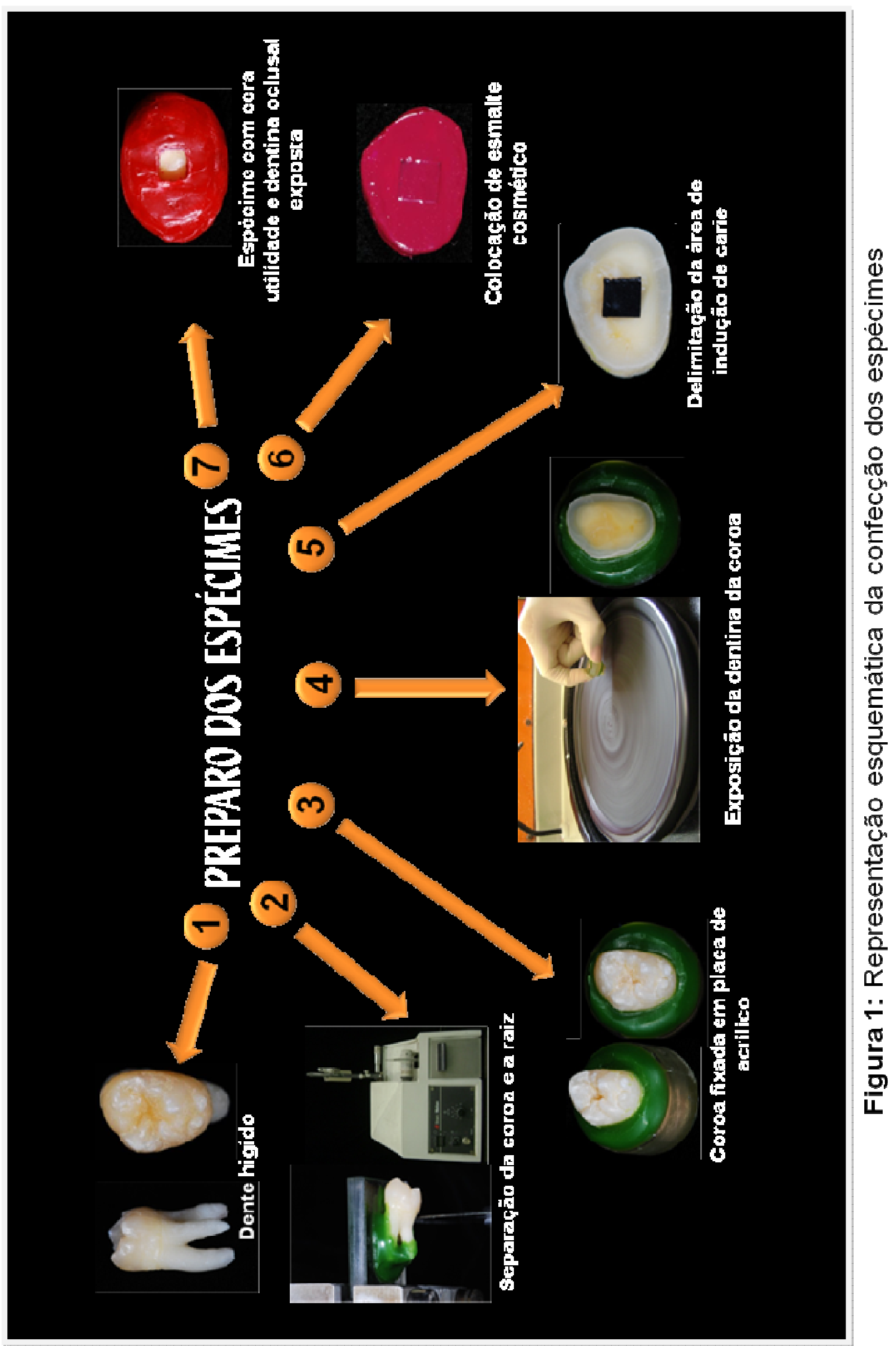




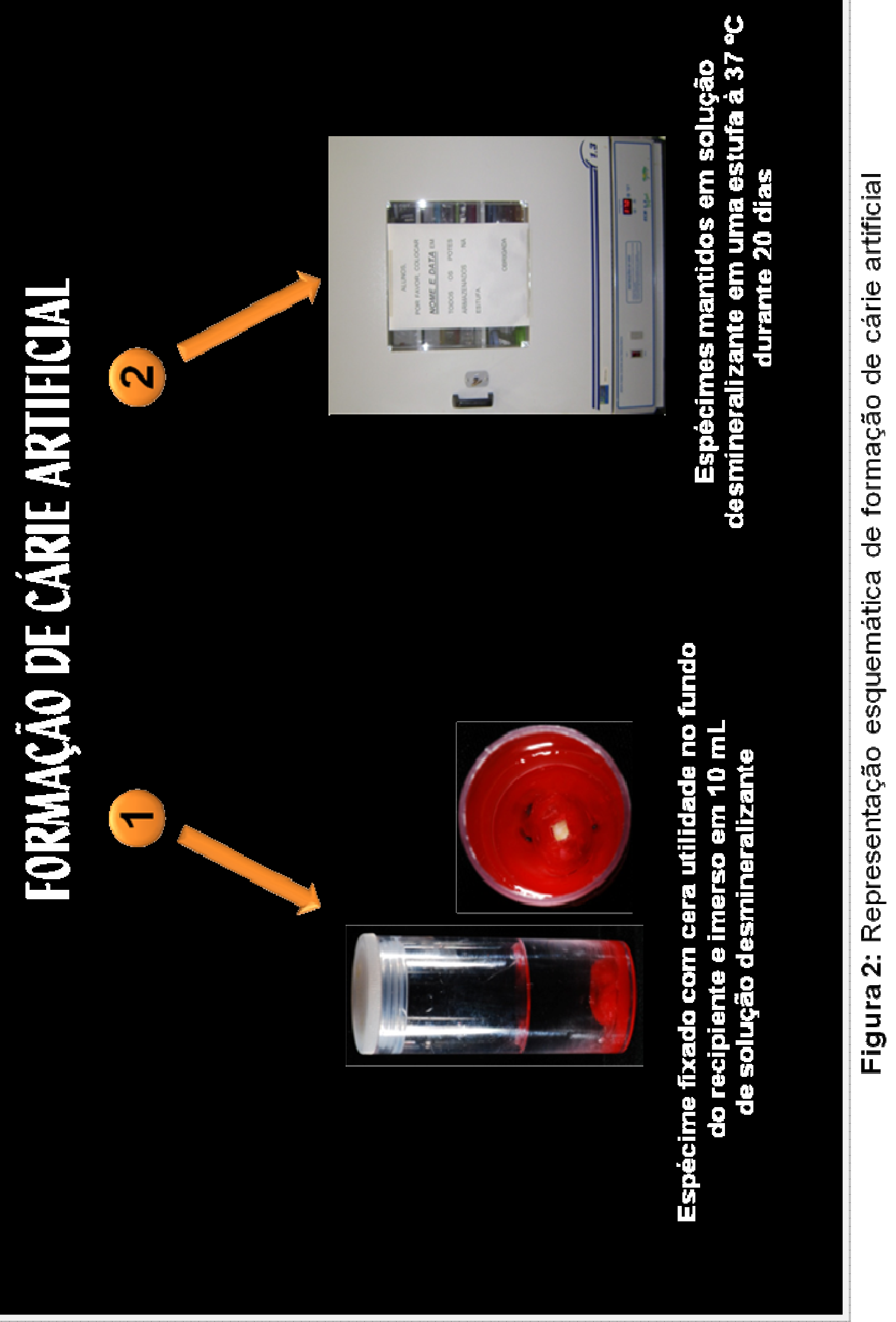




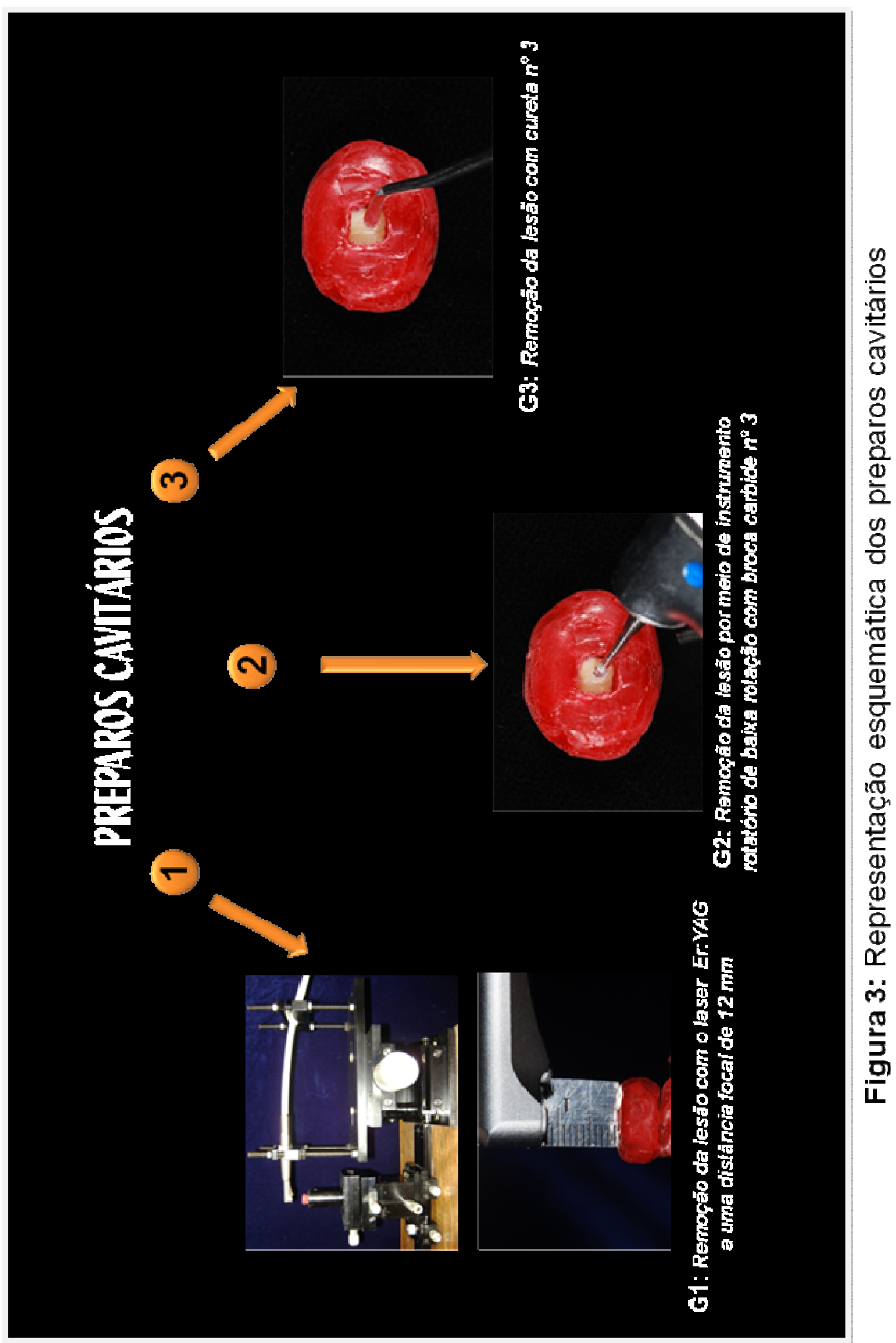




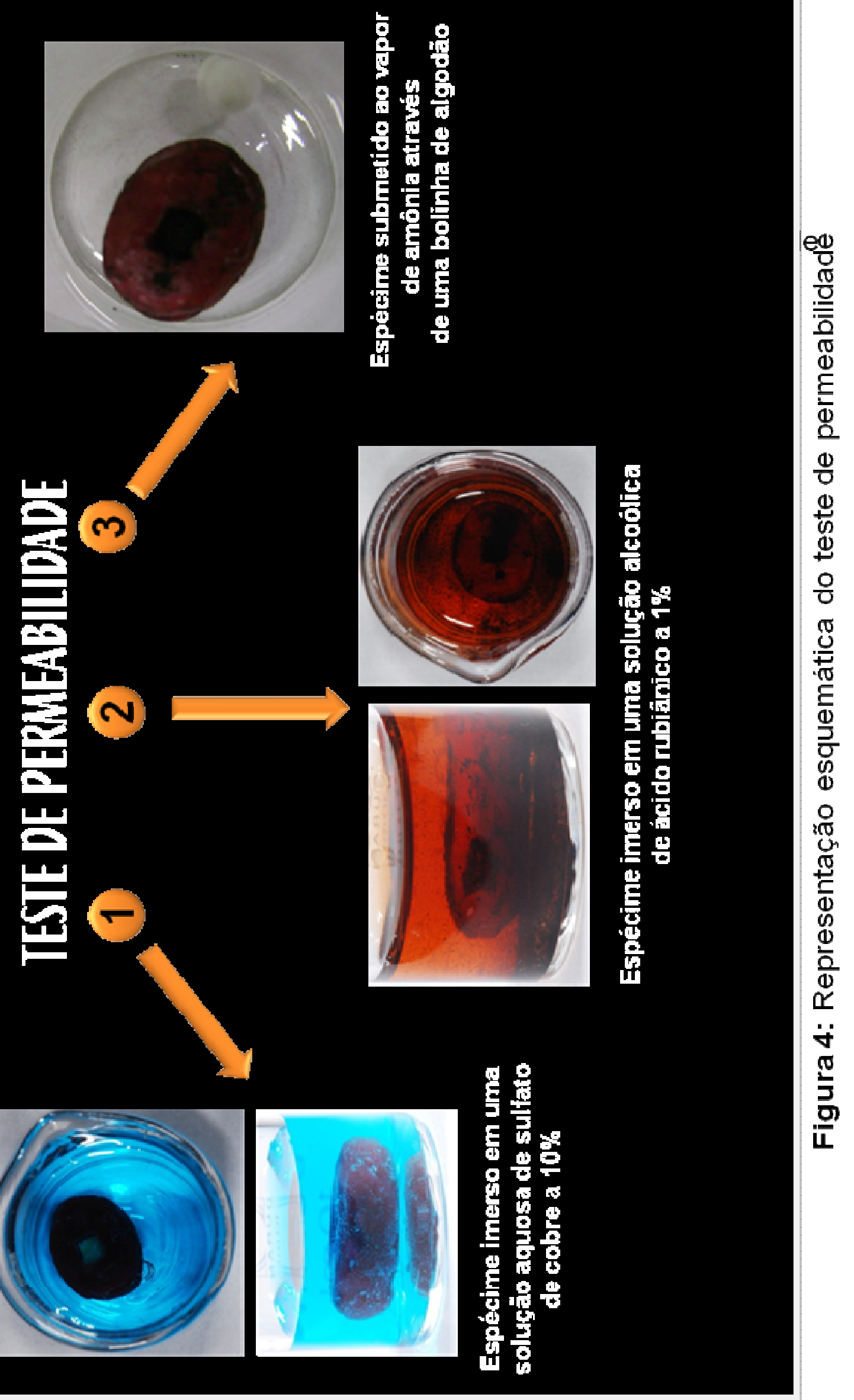




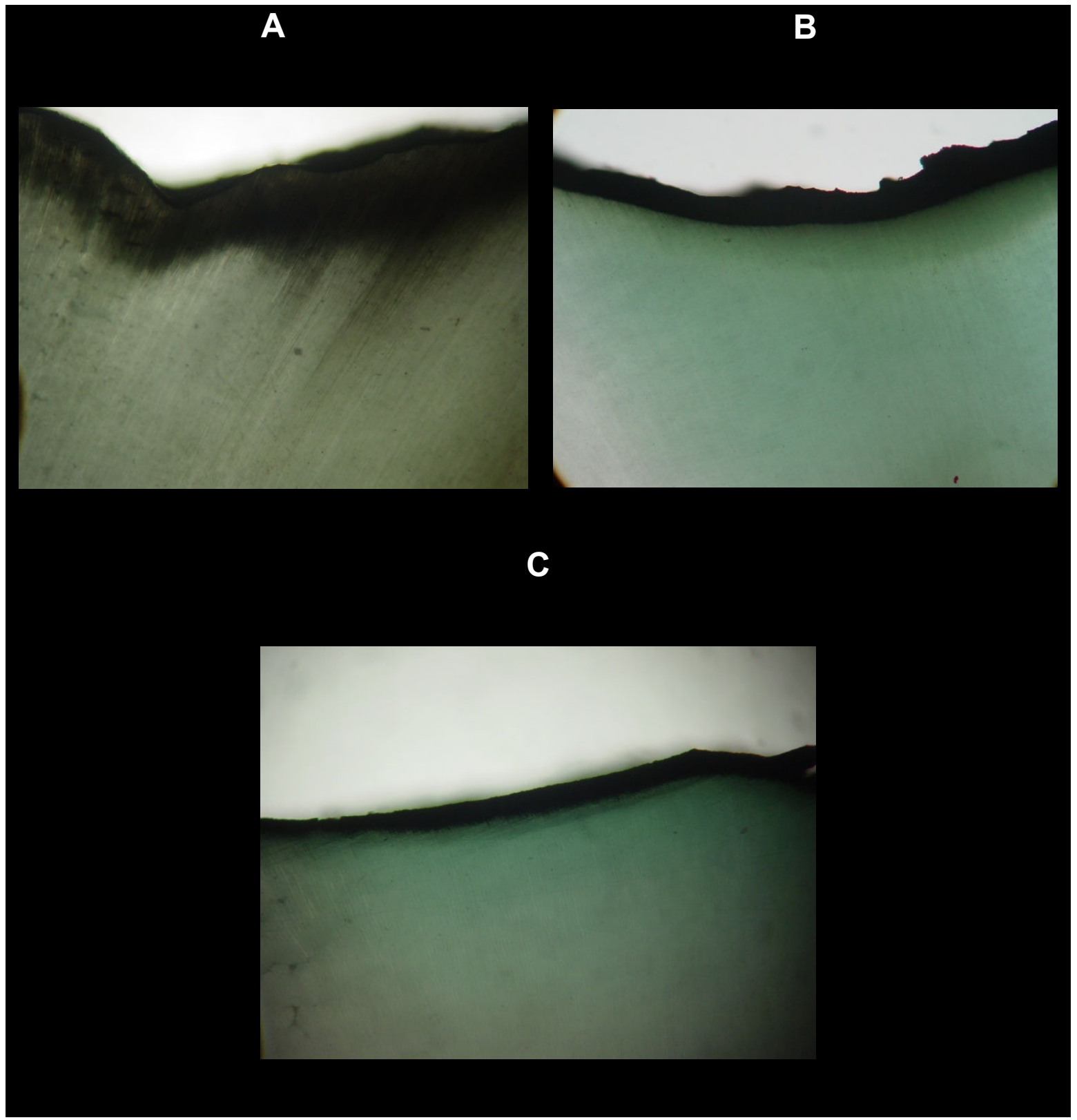

Figura 5: Imagens obtidas através da microscopia de luz com aumento de 40 vezes. A - Remoção de cárie com laser Er:YAG $(200 \mathrm{~mJ} / 6 \mathrm{~Hz})$. B - Remoção da cárie com baixa rotação. $\mathbf{C}$ - Remoção da cárie com cureta. 
4 Resultados 


\section{Resultados}

\subsection{Permeabilidade dentinaria}

$\mathrm{Na}$ análise dos dados observou-se que os métodos de remoção de cárie influenciaram na permeabilidade do tecido dentinario remanescente, sendo que o grupo do laser Er:YAG foi o que apresentou maior penetração do agente traçador e estatisticamente significante $(p<0,05)$ em relação aos demais grupos. A cureta e a broca apresentaram resultados semelhantes entre si. (Tabela 1 e Figura 6).

Tabela 1: Mediana, media e desvio padrão em $\mu \mathrm{m}$ da permeabilidade da dentina remanescente

\begin{tabular}{cccc}
\hline & Mediana* & Media & DP $( \pm)$ \\
\hline Laser & 15,66 a & 17,58 & 8,15 \\
Er:YAG & & & \\
Cureta & 4,76 b & 6,60 & 3,97 \\
Broca & 4,89 b & 5,50 & 2,24 \\
& & & \\
\hline
\end{tabular}

* mesma letra não houve significância estatística 
Box Plot

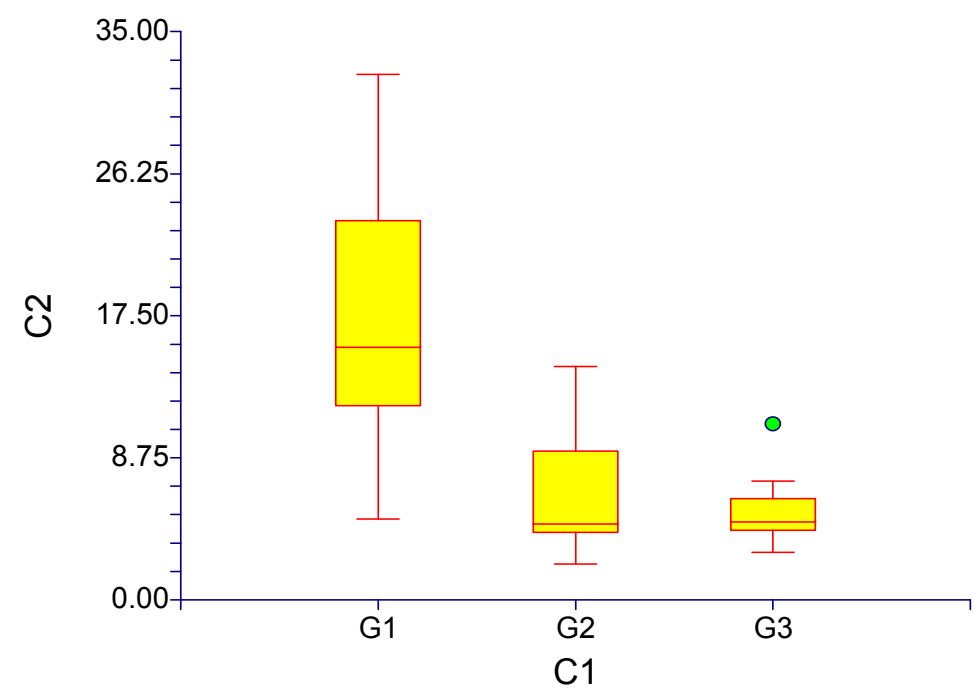

Figura 6: Box plot dos grupos estudados, com relação à permeabilidade da dentina remanescente.

\subsection{Remanescente de dentina desmineralizada}

$\mathrm{Na}$ análise do tecido desmineralizado remenescente pode-se observar que não houve diferença estatística significante entre os métodos de remoção de cárie, todos os grupos estudados deixaram remanescente de dentina desmineralizada no fundo da cavidade. (Tabela 2 e Figura 7). 
Tabela 2: Mediana, media e desvio padrão em $\mu \mathrm{m}$ do remanescente dentinario desmineralizado.

\section{Mediana* $^{*}$ Media $\quad$ DP $( \pm)$}

\begin{tabular}{cccc}
\hline Laser & 12,22 a & 10,61 & 4,00 \\
Er:YAG & & & \\
Cureta & $8,33 a$ & 8,45 & 2,68 \\
Broca & 11,93 a & 11,05 & 4,37 \\
\hline
\end{tabular}

* mesma letra não houve significância estatística

Box Plot

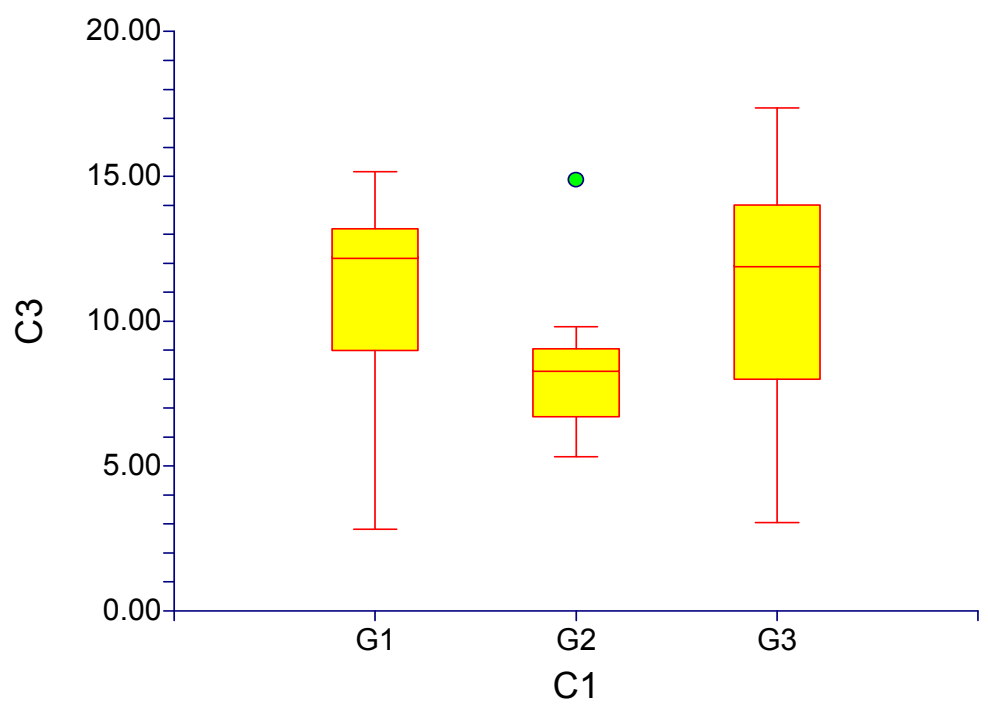

Figura 7: Box plot dos grupos estudados, com relação ao remanescente dentinario desmineralizado.

Em relação à correlação dos dados pode-se observar que de uma maneira geral houve uma moderada correlação positiva $(r=0,47)$ entre a permeabilidade e o remanescente de dentina desmineralizada. Contudo quando se analisou individualmente cada grupo pode-se observar que o grupo 1 apresentou uma forte 
correlação entre os dois achados $(r=0,86)$ e os grupos 2 e 3 moderada correlação $(r=0,32$ e $r=0,56$ respectivamente).

\subsection{Análise morfológica}

Pode-se observar que para o grupo com laser não houve a formação de smear layer, com as embocaduras dos túbulos abertas, remoção mais intensa da dentina intertubular e protrusão da dentina peritubular. Observou-se também a presença de trincas e fissuras, principalmente na porção mais profunda da dentina. (Figura 8)

No grupo com broca encontrou uma superfície com smear layer, apresentando-se obstruídas as embocaduras dos túbulos (Figura 9). O mesmo pode ser observado para o grupo com cureta (Figura 10) 

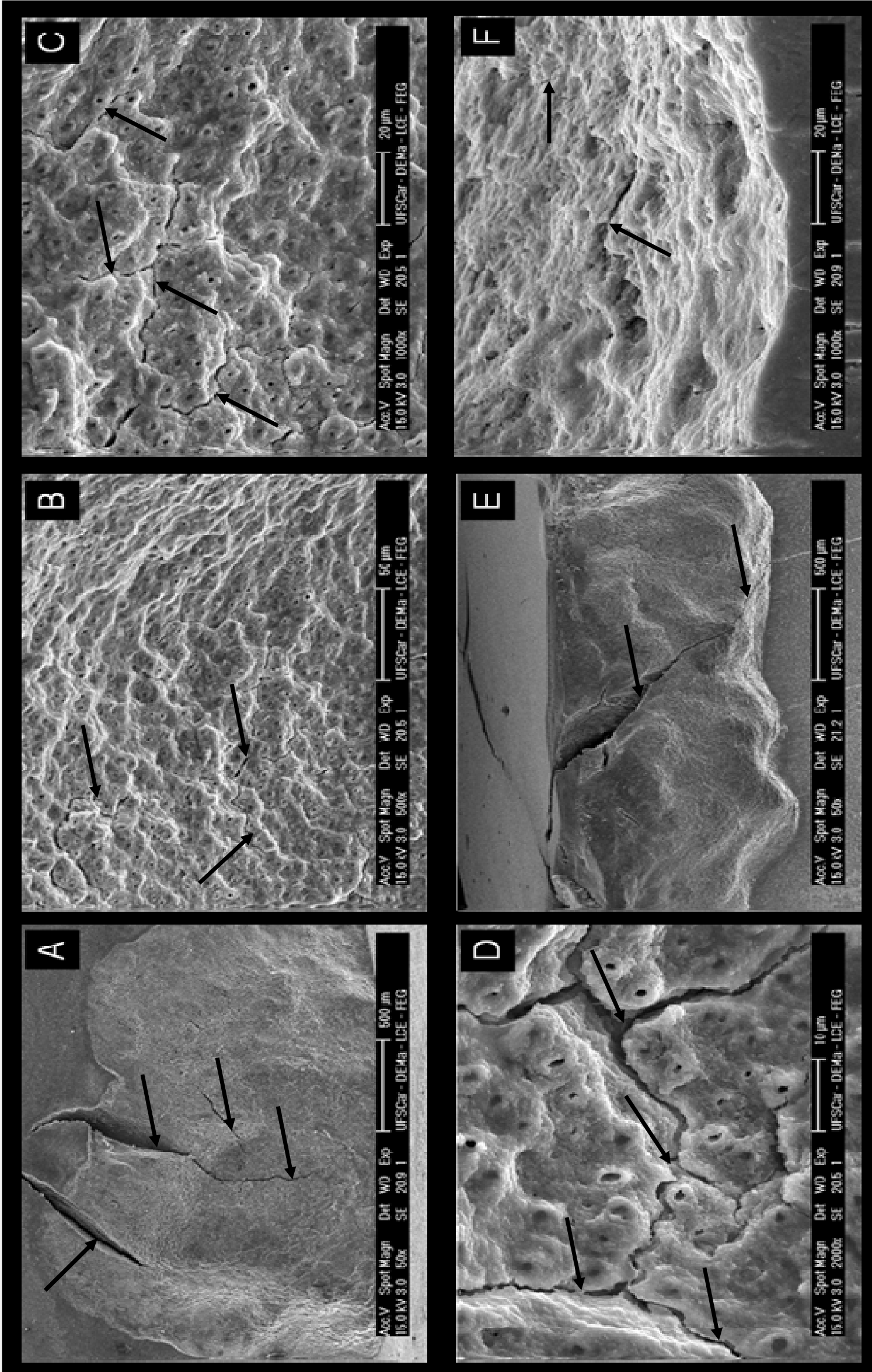

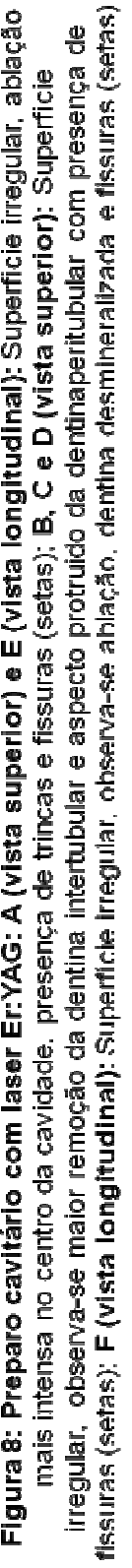



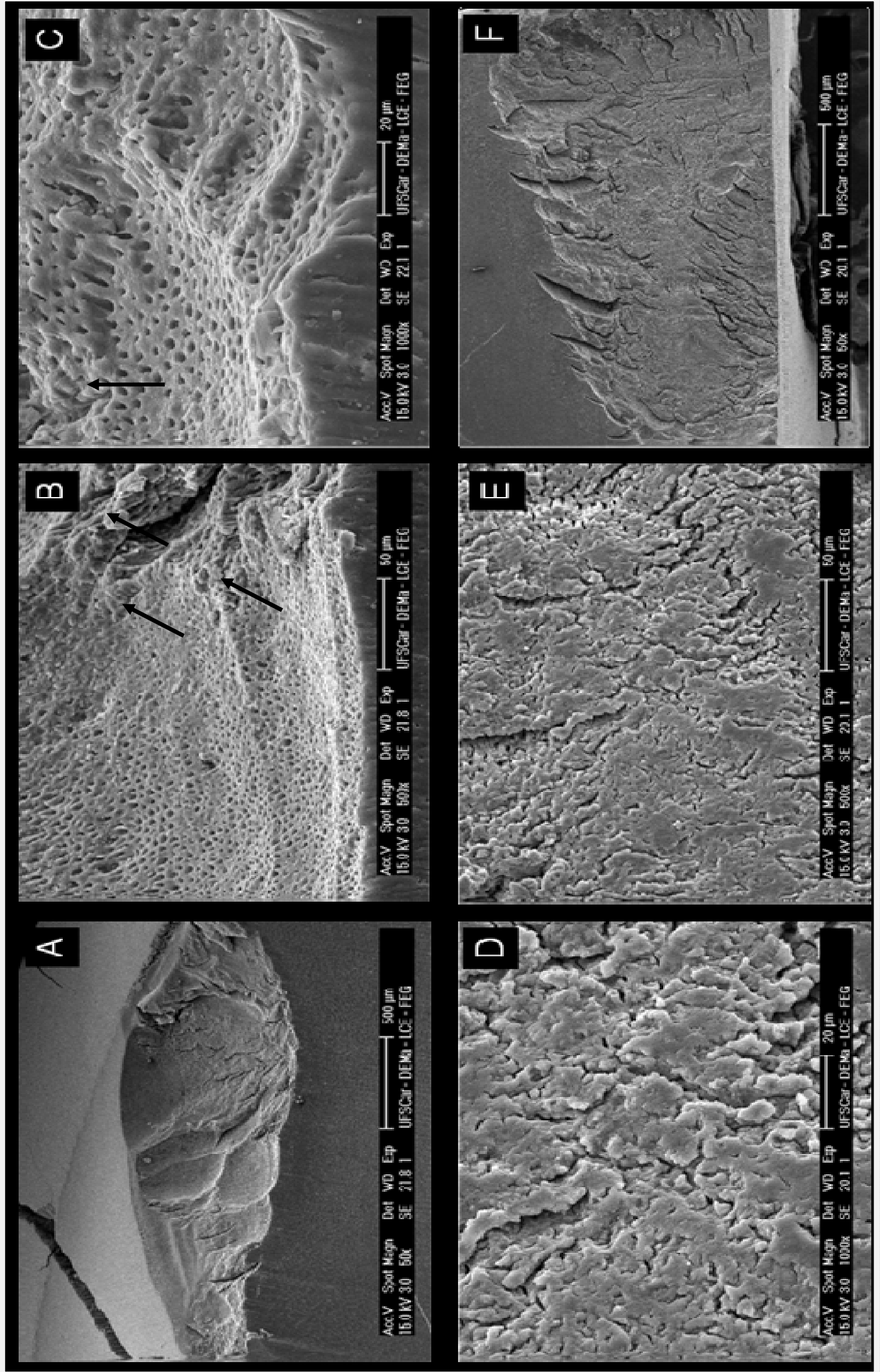

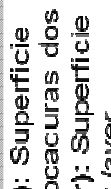
言品要 은은 윽 宩曹 II 娄

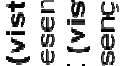
山言鱾 界品

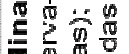
过要 面응 은 흔

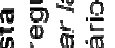
政要 4 is 总要弯 등 $\because$ ป็

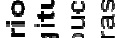

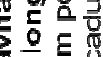
8 중 证 a क

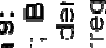
눈 는 

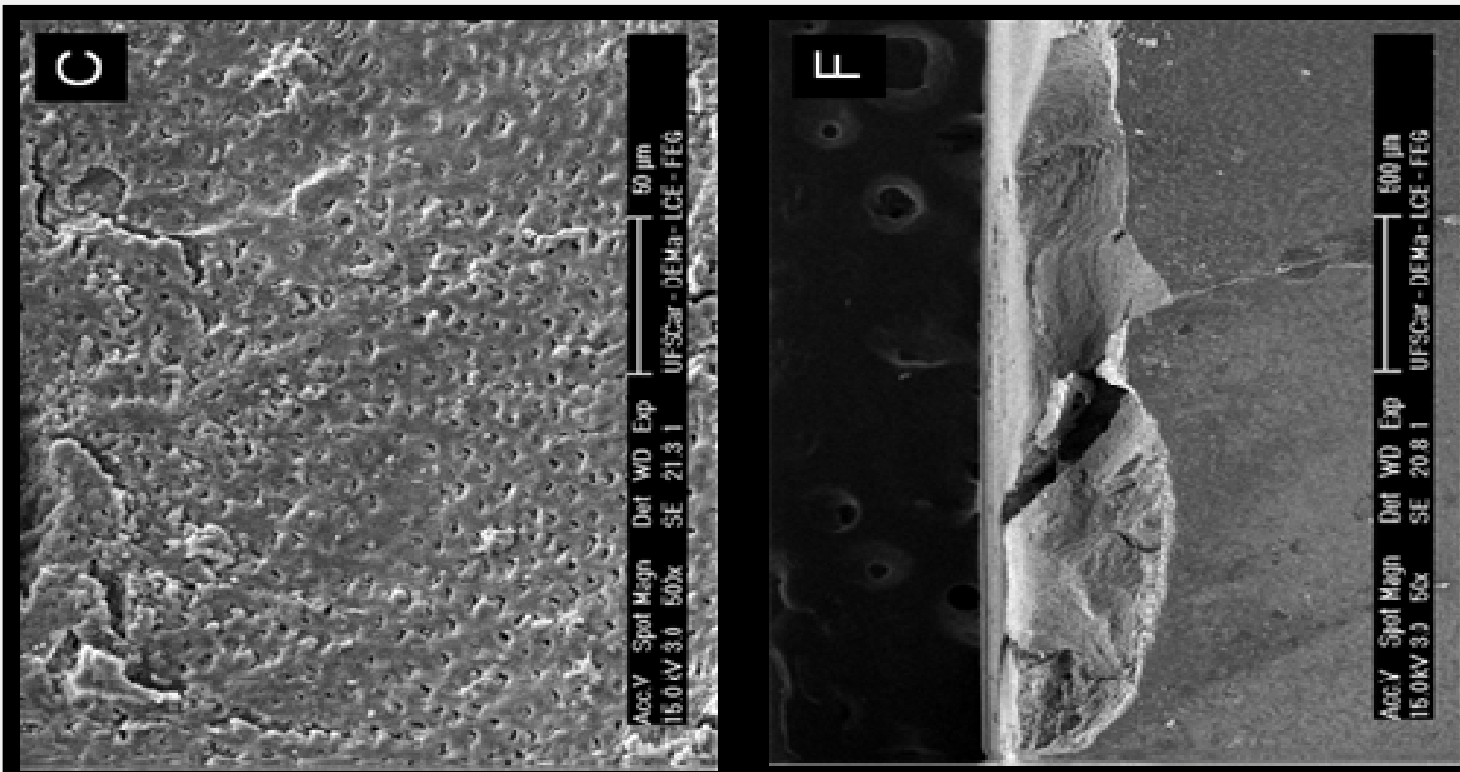

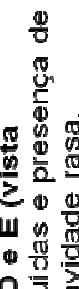
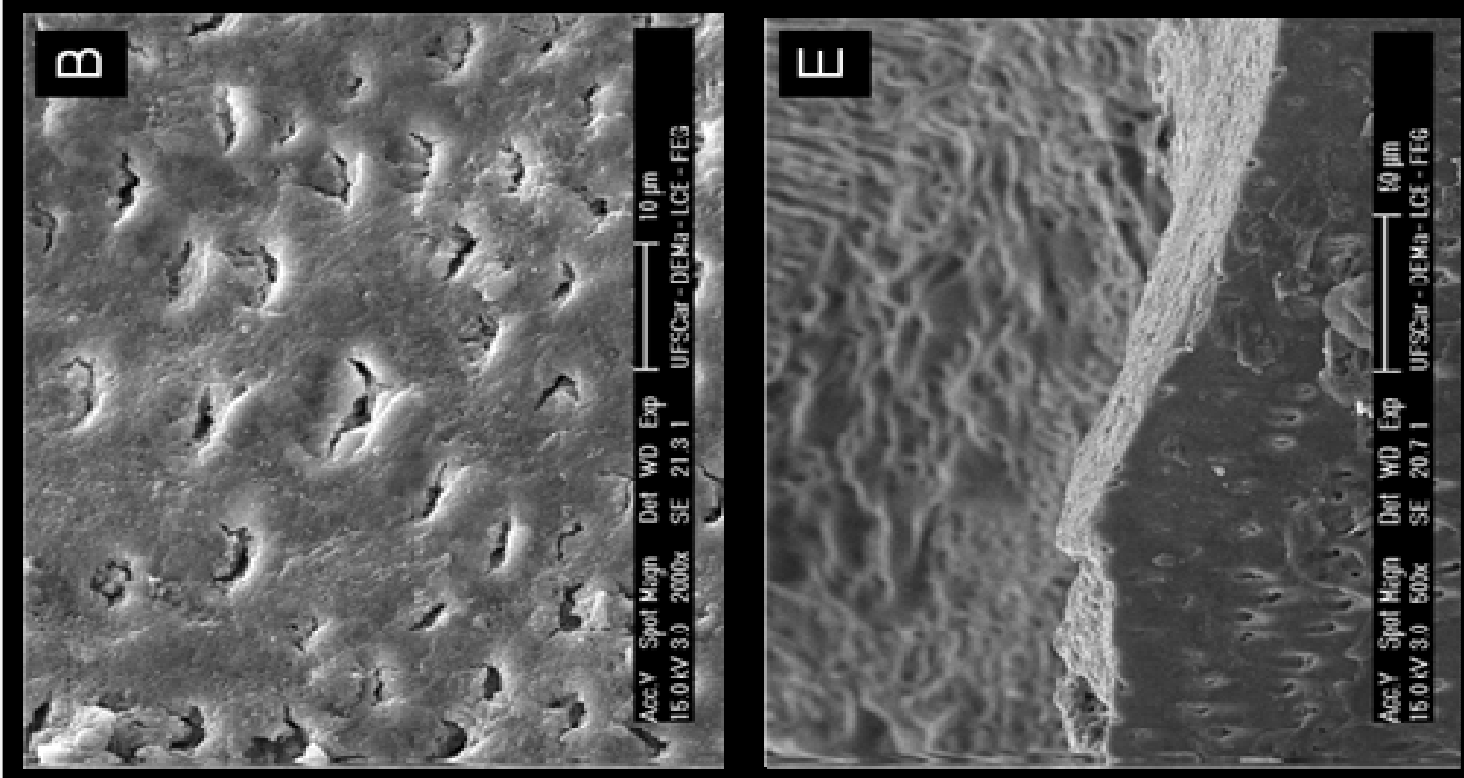

믈

容。

음음

g in

可迹

54

要

类

U

综:

离留

娄业

류

E

응

은 훟무

突

흘

올

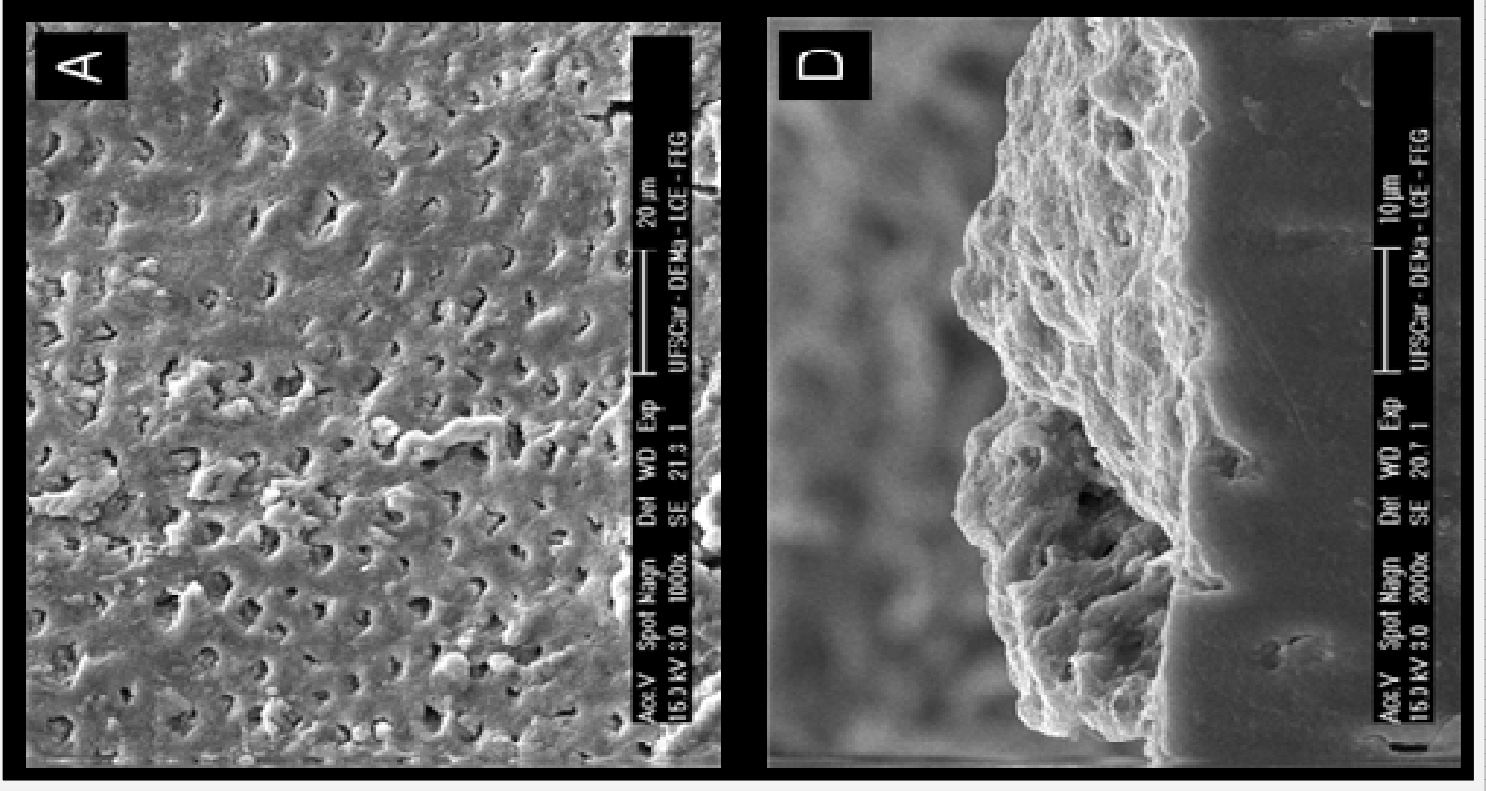

능한

口 ㄴ

关亭

की

要豪

흠 
5 Discussão 


\section{Discussão}

Durante o preparo cavitário com instrumentos manuais ou rotatórios, foi observada uma a remoção parcial ou total do tecido desmineralizado, deixando na superfície uma camada de detritos, denominada smear layer (Pashley, 1984; Tao et al., 1988). Essa camada não aderida à dentina é composta por minerais e materiais orgânicos, apresentando uma espessura variada $(0,05 \mu \mathrm{m}$ a 10,0 $\mu \mathrm{m})$, com relação à morfologia de seus constituintes, esta é determinada de acordo com o instrumento utilizado e a região da dentina atingida (Gwinnett, 1984; Pashley, 1992). Sendo observada como uma camada amorfa, revestindo a dentina intertubular, com projeções para o interior dos túbulos dentinários, ficando obliterada grande parte da entrada destes túbulos, desta forma criando uma barreira entre material adesivo e substrato dental.

Com o intuito de se reduzir ou eliminar o desconforto do paciente, remover seletivamente o tecido cariado e proporcionar uma superfície limpa, o laser tem sido estudado para sua utilização na clínica odontológica. Entre os sistemas de laser, o laser Er:YAG se destaca por realizar preparos cavitários através de uma ablação seletiva da cárie sem danificar a estrutura dental (Osuka et al., 2009), como também elimina as bactérias do preparo (Eberhard et al., 2005) e não forma smear layer nas cavidades preparadas com este equipamento, deixando os túbulos dentinários abertos, favoráveis à adesão do material restaurador ao substrato dental (Shigetani et al., 2002; Baraba et al., 2009), além de ser um procedimento bem aceito pelos pacientes (Keller et al., 1998).

O laser Er:YAG possui como meio ativo um cristal de ítrio-aluminio-granada (Ytrium-Aluminum-Garnet), dopados com íons érbio, que quando estimulado por uma lâmpada de flash dentro de um ressonador, emite um comprimento de onda de

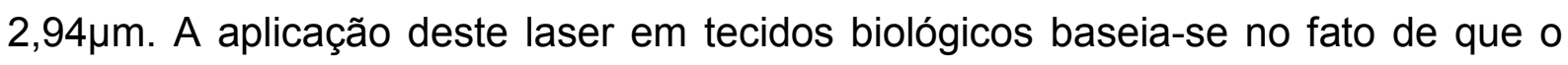
comprimento de onda emitido pelo laser coincide com o pico máximo de absorção da água e dos radicais hidroxila presentes nos tecidos dentais. Assim, a exposição ao laser promove vaporização da água e dos componentes hidratados dos tecidos, 
causando um rápido aquecimento seguido por microexplosões resultantes do aumento da pressão interna das moléculas teciduais, que leva a ejeção do substrato em forma de partículas microscópicas, gerando um efeito fotomecânico (Keller; Hibst, 1989).

O processo de ablação da estrutura dental consome a maior parte da energia irradiada, sendo liberada uma fração aos tecidos dentais remanescentes que resulta em um aquecimento desse tecido (Hossain, et al., 1999). Com tudo diversos métodos demonstram que, desde que usado sob refrigeração ideal, o laser Er:YAG não causa danos térmicos à polpa dental (Aoki et al., 1998; Attrill et al., 2004; Geraldo-Martins et al., 2005), já que a refrigeração a água impede o aquecimento do substrato dental, além de favorecer a ablação e a obtenção de cavidades limpas (Hoke et al., 1990; Burkes et al., 1992; Dostálová et al., 1996).

Também foi encontrado em outros estudos, que devido ao maior conteúdo de água na dentina sua ablação e mais intensa do que a do esmalte (Hibst; Keller, 1989; Armengol et al., 1999). Por outro lado, a dentina intertubular apresenta maior quantidade de água e hidroxiapatita que a dentina peritubular, pelo qual no presente estudo observou-se uma remoção mais intensa da dentina intertubular e protrusão da dentina peritubular, coincidindo com estudos da literatura (Armengol et al., 1999; Raucci-Neto et al., 2010). Da mesma forma, alguns estudos relatam maior ablação da dentina cariada, já que esta apresenta uma alta permeabilidade e, conseqüentemente, é mais úmido do que dentina hígida (Roth et al., 1995). Possibilitando, desta forma, um menor desgaste de dentina quando comparado com o método convencional (Eberhard et al., 2008), realizando a remoção do tecido dentinário infectado, sem presença residual de bactérias no preparo (Eberhard et al., 2005).

Em relação aos parâmetros do laser Er:YAG empregados para o preparo cavitário, a freqüência merece destaque por estar diretamente relacionada ao aumento da temperatura, pois, com o aumento da taxa de repetição de pulsos, ocorre uma maior liberação de calor (Raucci-Neto et al., 2010). Parte desta energia é dissipada e resulta em deposição de calor residual, que pode provocar áreas de fusão e recristalização (Corona et al., 2007). No presente estudo empregou-se a 
energia de $200 \mathrm{~mJ}$ e freqüência de $6 \mathrm{~Hz}$ baseado em resultados anteriores (RaucciNeto et al., 2010) em que verificou que estes parâmetros promoveram um aumento de temperatura aceitável e mais seletivo para remoção do tecido desmineralizado,

Nos resultados obtidos, foi observado que o método de preparo cavitário influenciou na permeabilidade do tecido, apresentando o laser Er:YAG a maior permeabilidade quando comparado ao instrumento rotatório e ao manual. Este fato provavelmente pode ser explicado devido a que este método não promoveu a formação da smear layer durante o preparo cavitário e deixando os túbulos dentinários abertos, sendo resultados igualmente observados por outros autores (Visuri et al., 1996; Shigetani et al., 2002; Chinelatti et al., 2004; Baraba et al., 2009). Por outra parte os autores também relatam a presença de trincas e fissuras (Martinez-Insua et al., 2000; Ramos et al., 2002) no preparo cavitário com o laser Er:YAG semelhantemente ao encontrado no presente estudo, principalmente na porção mais profunda da dentina, podendo ter contribuído a maior permeabilidade da dentina. Em relação às superfícies dentinarias após a remoção da carie com a cureta e a broca em baixa rotação foi observada a presença de smear layer e oclusão das embocaduras dos túbulos dentinarios, principalmente da porção mais profunda da cavidade (Yazici et al., 2002) o qual pode ter interferido no grau de permeabilidade dentinaria (Elgalaid et al., 2007).

Apesar disso, a literatura apresenta resultados contraditórios, observando-se que este laser pode levar à produção de áreas de fusão e recristalização nas superfícies dentais, criando áreas hipermineralizadas e menos permeáveis (Corona et al., 2007). Também, outros estudos da literatura relatam que este tipo de laser causa a perda d'água da dentina, a alteração da estrutura e composição do colágeno e a incorporação do radical $\mathrm{OH}$, dificultando a adesividade (Ceballos et al., 2002; De Munk et al., 2002; Bachman et al., 2005; Brulat et al., 2009; Ferreira et al., 2009; Ramos, 2010).

Com relação ao tipo de resposta dos tecidos dentários frente à com irradiação do laser de Er:YAG, foi encontrado em vários estudos uma grande influencia dos parâmetros utilizados no laser, como o modo de irradiação, a densidade de energia, a distância focal e a freqüência (Igarashi et al., 2008; Raucci-Neto et al., 2010). 
Sendo observados bons resultados, através da utilização do feixe do laser no modo não-contato e focado, pois proporcionam uma maior intensidade de ablação e melhor habilidade do laser produzir uma estrutura superficial micro retentiva, sendo a freqüência considerada um fator de grande influencia devido ao acúmulo de calor nos tecidos e na capacidade de ablação (Raucci-Neto et al., 2010; Raucci-Neto et al., 2007; Corona, 2007).

Com relação à capacidade de remoção de tecido desmineralizado não foi encontrada uma diferença estatística entre os três métodos analisados. Em estudos anteriores, a remoção de carie pelo laser Er:YAG tem-se mostrado muito eficiente (Aoki et al., 1998; Keller et al., 1998; Armengol et al., 1999), como também, em um estudo prévio (Raucci-Neto et al., 2010) observou-se que o uso do laser Er:YAG na frequencia de $6 \mathrm{~Hz}$ e $10 \mathrm{~Hz}$ proporcionou uma dentina remanescente desmineralizada com uma rede ultra-estrutural de matriz de colágeno.

Por outro lado, o método mecânico rotatório, em comparação com os outros métodos observados, se caracteriza por ser um método de remoção não seletivo (Banerjee et al., 2000), dependendo muito do operador a quantidade de tecido removido, existindo menor probabilidade de deixar remanescente de tecido desmineralizado.

No presente estudo poder-se observar que a utilização da broca proporcionou uma superfície com tecido desmineralizado no fundo da cavidade, isto provavelmente ocorreu em função do operador de ter o cuidado de realizar preparo mais conservativo e cuidadoso.

Entretanto a remoção manual da carie através da cureta ao contrario da broca, foi visto que através de esta existe um maior risco de deixar remanescente de tecido desmineralizado (Frencken, et al., 1998; Smales; Fang 1999), o que não ocorreu no presente estudo, em que observou uma menor quantidade de tecido desmineralizado em comparação aos outros métodos utilizados, provavelmente pode-se explicar este achado em função que a pressão empregada para a remoção do tecido desmineralizado é difícil de ser controlada e assim pode acarretar uma remoção maior do tecido, por sua vez a remoção de cárie com cureta esta 
principalmente relacionada com a habilidade e performance do operador (Mickenautsch; Grossman, 2006).

Com respeito à correlação entre a permeabilidade e remanescente de dentina desmineralizada, pode-se observar no presente estudo uma correlação positiva entre o remanescente e a permeabilidade para o grupo Laser, ou seja, quanto mais tecido desmineralizado mantido na dentina subjacente da cavidade, maior é a permeabilidade do tecido, provavelmente devido o tecido desmineralizado ser mais úmido o que favorece a penetração do agente traçador, somando-se este resultado aos outros achados considerados como possíveis contribuintes à maior permeabilidade dentinária.

No grupo da broca e cureta houve uma fraca e moderada correlação devido aos diferentes resultados encontrados na permeabilidade dentinária e dentina desmineralizada remanescente, isto pode-ser devido à presença de smear layer na superfície dentinária, formando de esta maneira uma barreira que impede ou dificulta a penetração de substancias da superfície dentinária ao tecido desmineralizado

A pesar de que a remoção da carie com o laser Er:YAG se trata de um método eficaz, biocompatível e conservador, além de apresentar vantagens em relação aos instrumentos rotatórios e manuais, existe uma escassez de estudos realizados da irradiação do laser Er:YAG na superfície cariada dentinária, que a sua vez torna difícil neste estudo uma comparação de resultados.

Desta forma, se faz necessária a realização de mais estudos dos efeitos da irradiação do laser Er:YAG na superfície cariada dentinária, já que o estudo de este substrato esta relacionado com a permeabilidade dentinária e tipo de interação do adesivo e cimento odontológico na dentina remanescente. 
6 Conclusão 


\section{Conclusã̃o}

Baseado nos resultados obtidos pelo presente estudo pode-se concluir que:

* O laser Er:YAG promoveu um tecido dentinário mais permeável, encontrado-se as embocaduras dos túbulos dentinarios abertas sem formação de smear layer, formação de trincas e fissuras.

* O método de preparo cavitário não influenciou na seletividade na remoção do tecido desmineralizado.

* O laser apresentou correlação positiva entre a permeabilidade e remanescente. 


\section{Referências Biblio@ráfícas 1}

1. Aoki A, Ishikawa I, Yamada $\mathrm{T}$, Otsuki M, Watanabe H, Tagami J, Ando $\mathrm{Y}$, Yamamoto $\mathrm{H}$. Comparison between Er:YAG laser and conventional technique for root caries treatment in vitro. J Dent Res. 1998 Jun;77(6):1404-14.

2. Aranha AC, De Paula Eduardo C, Gutknecht N, Marques MM, Ramalho KM, Apel C. Analysis of the interfacial micromorphology of adhesive systems in cavities prepared with Er,Cr:YSGG, Er:YAG laser and bur. Microsc Res Tech. 2007 Aug;70(8):745-51.

3. Armengol V, Jean A, Rohanizadeh R, Hamel H. Scanning electron microscopic analysis of diseased and healthy dental hard tissues after Er:YAG laser irradiation: in vitro study. J Endod. 1999 Aug;25(8):543-6.

4. Attrill DC, Davies RM, King TA, Dickinson MR, Blinkhorn AS. Thermal effects of the Er:YAG laser on a simulated dental pulp: a quantitative evaluation of the effects of a water spray. J Dent. 2004 Jan;32(1):35-40.

5. Bachmann L, Diebolder R, Hibst R, Zezell DMChanges in chemical composition and collagen structure of dentine tissue after erbium laser irradiation. Spectrochim Acta A Mol Biomol Spectrosc. 2005 Sep;61(1112):2634-9.

6. Banerjee A, Kidd EAM, Watson TF. In vitro evaluation of five alternative methods of carious dentine excavation. Caries Research. 2000;34(2):144-150.

7. Baraba A, Miletic I, Krmek SJ, Perhavec T, Bozic Z, Anic I. Ablative potential of the erbium-doped yttrium aluminium garnet laser and conventional handpieces: a comparative study. Photomed Laser Surg. 2009 Dec;27(6):9217. 
8. Bertrand MF, Semez G, Leforestier E, Muller-Bolla M, Nammour S, Rocca JP. Er:YAG laser cavity preparation and composite resin bonding with a singlecomponent adhesive system: relationship between shear bond strength and microleakage. Lasers Surg Med. 2006 Jul;38(6):615-23.

9. Brulat N, Rocca JP, Leforestier E, Fiorucci G, Nammour S, Bertrand MF. Shear bond strength of self-etching adhesive systems to Er:YAG-laserprepared dentin. Lasers Med Sci. 2009 Jan;24(1):53-7.

10. Burkes EJ Jr, Hoke J, Gomes E, Wolbarsht M. Wet versus dry enamel ablation by Er:YAG laser. J Prosthet Dent. 1992 Jun;67(6):847-51.

11. Ceballos L, Toledano M, Osorio R, Tay FR, Marshall GW. Bonding to ErYAG-laser-treated dentin. J Dent Res. 2002 Feb;81(2):119-22.

12. Ceballos L, Toledano M, Osorio R, García-Godoy F, Flaitz C, Hicks J. ERYAG laser pretreatment effect on in vitro secondary caries formation around composite restorations. Am J Dent. 2001 Feb;14(1):46-9.

13. Chaiyavej S, Yamamoto $H$, Takeda A, Suda $H$. Response of feline intradental nerve fibers to tooth cutting by Er:YAG laser. Lasers Surg Med. 2000;27(4):341-9.

14. Chalmers, JM. Minimal intervention dentistry: part 2. Strategies for addressing restorative challenges in older patients. J Can Dent Assoc. 2006 Jun;72(5):435-40.

15. Chinelatti MA, Ramos RP, Chimello DT, Borsatto MC, Pécora JD, PalmaDibb RG. Influence of the use of Er:YAG laser for cavity preparation and surface treatment in microleakage of resin-modified glass ionomer restorations. Oper Dent. 2004 Jul-Aug;29(4):430-6. 
16. Corona SA, de Souza AE, Chinelatti MA, Borsatto MC, Pécora JD, PalmaDibb RG. Effect of energy and pulse repetition rate of Er: YAG laser on dentin ablation ability and morphological analysis of the laser-irradiated substrate. Photomed Laser Surg. 2007 Feb;25(1):26-33.

17. Correa-Afonso AM, Pécora JD, Palma-Dibb RG. Influence of pulse repetition rate on temperature rise and working time during composite filling removal with the Er:YAG laser. Photomed Laser Surg. 2008 Jun;26(3):221-5.

18. De Munck J, Van Meerbeek B, Yudhira R, Lambrechts P, Vanherle G. Microtensile bond strength of two adhesives to Erbium:YAG-lased vs. bur-cut enamel and dentin. Eur J Oral Sci. 2002 Aug;110(4):322-9.

19.Dominici JT, Eleazer PD, Clark SJ, Staat RH, Scheetz JP. Disinfection/sterilization of extracted teeth for dental student use. J Dent Educ. 2001 Nov;65(11):1278-80.

20. Dostálová T, Jelínková $H$, Krejsã O, Hamal H. Evaluation of the surface changes in enamel and dentin due to possibility of thermal overheating induced by Erbium:YAG laser radiation. Scanning Microsc. 1996;10(1):28590.

21. Eberhard J, Bode K, Hedderich J, Jepsen S. Cavity size difference after caries removal by a fluorescence-controlled Er:YAG laser and by conventional bur treatment. Clin Oral Investig. 2008 Dec;12(4):311-8.

22. Eberhard J, Eisenbeiss AK, Braun A, Hedderich J, Jepsen S. Evaluation of selective caries removal by a fluorescence feedback-controlled Er:YAG laser in vitro. Caries Res. 2005 Nov-Dec;39(6):496-504.

23. Elgalaid TO, Creanor SL, Creanor S, Hall AF. The permeability of natural dentine caries before and after restoration: An in vitro study. J Dent. 2007 Aug;35(8):656-63. 
24. Ferreira LS, Apel C, Francci C, Simoes A, Eduardo CP, Gutknecht N. Influence of etching time on bond strength in dentin irradiated with erbium lasers. Lasers Med Sci. 2010 Nov;25(6):849-54.

25. Frencken JE, Makoni F, Sithole WD. ART restorations and glass ionomer sealants in Zimbadwe: survival after 3 years. Community Dentistry and Oral Epidemiology. 1998;26(6): 372-381.

26. Frencken JE, Pilot $T$, Songpaisan $Y$, Phantumvanit $P$. Atraumatic restorative treatment (ART): rationale, technique, and development. Journal of Public Health Dentistry. 1996;56(3):135-140.

27. Geraldo-Martins VR, Tanji EY, Wetter NU, Nogueira RD, Eduardo CP. Intrapulpal temperature during preparation with the Er:YAG laser: an in vitro study. Photomed Laser Surg. 2005 Apr;23(2):182-6.

28. Gwinnett AJ. Smear layer: morphological considerations. Oper Dent Suppl. 1984;3:2-12.

29. Hibst, R. Lasers for caries removal and cavity preparation: state of the art and future directions. J Oral Laser Appl. 2002; 2: 203-11.

30. Hoke JA, Burkes EJ Jr, Gomes ED, Wolbarsht ML. Erbium:YAG (2.94 mum) laser effects on dental tissues. J Laser Appl. 1990;2(3-4):61-5.

31. Hossain M, Nakamura Y, Yamada Y, Kimura Y, Nakamura G, Matsumoto K. Ablation depths and morphological changes in human enamel and dentin after Er:YAG laser irradiation with or without water mist. J Clin Laser Med Surg. 1999 Jun;17(3):105-9.

32. Igarashi A, Kato J, Takase Y, Hirai Y. Influence of output energy and pulse repetition rate of the Er:YAG laser on dentin ablation. Photomed Laser Surg. 2008 Jun;26(3):189-95. 
33. Jacobsen PH, Robinson PB. Basic techniques and materials for conservative dentistry: I Cavity preparation. J Dent. 1980 Dec;8(4):283-91.

34. Keller U, Hibst R, Geurtsen W, Schilke R, Heidemann D, Klaiber B, Raab WH. Erbium:YAG laser application in caries therapy. Evaluation of patient perception and acceptance. J Dent. 1998 Nov;26(8):649-56.

35. Keller U, Hibst R. [Ablative effect of an Er:YAG laser on enamel and dentin]. Dtsch Zahnarztl Z. 1989 Aug;44(8):600-2.

36. Kidd EA, Fejerskov O. What constitutes dental caries? Histopathology of carious enamel and dentin related to the action of cariogenic biofilms. J Dent Res. 2004;83(1):C35-8.

37. Kidd EA. How 'clean' must a cavity be before restoration?. Caries Res. 2004 May-Jun;38(3):305-13.

38. Kuboki, Y; Ohgushi, K; Fusayama, T. Collagen biochemistry of the two layers of carious dentin. J Dent Res. 1977 Oct; 56(10):1233-7.

39. Lizarelli Rde F, Moriyama LT, Bagnato VS. Ablation of composite resins using Er:YAG laser--comparison with enamel and dentin. Lasers Surg Med. 2003;33(2):132-9.

40. Martínez-Insua A, Da Silva Dominguez L, Rivera FG, Santana-Penín UA. Differences in bonding to acid-etched or Er:YAG-laser-treated enamel and dentin surfaces. J Prosthet Dent. 2000 Sep;84(3):280-8.

41. Mickenautsch S, Grossman E. Atraumatic Restorative Treatment (ART): factors affecting success. J Appl Oral Sci. 2006;14 Suppl:34-6. 
42. Mount GJ. A new paradigm for operative dentistry. Aust Dent J. 2007 Dec;52(4):264-70.

43. Murdoch-Kinch CA, McLean ME. Minimally invasive dentistry. J Am Dent Assoc. 2003 Jan;134(1):87-95.

44. Osuka K, Amagai T, Kukidome N, Takase Y, Aida S, Hirai Y. Effect of dentin hardness on ablation rate with Er:YAG laser. Photomed Laser Surg. 2009 Jun;27(3):395-9.

45. Pashley DH. Smear layer: physiological considerations. Oper Dent Suppl. 1984;3:13-29.

46. Pashley DH. Smear layer: overview of structure and function. Proc Finn Dent Soc. 1992;88 Suppl 1:215-24.

47. Pashley $\mathrm{DH}$. Dentin bonding: overview of the substrate with respect to adhesive material. Journal of Esthetic Dentistry. 1991;3(2):46-50.

48. Pashley DH, Livingston MJ, Reeder OW, Horner J. Effects of the degree of tubule occlusion on the permeability of human dentine in vitro. Archives of Oral Biology. 1978;23(12):1127-1133.

49. Parker S. Surgical lasers and hard dental tissue. $\mathrm{Br}$ Dent J. 2007 Apr;202(8):445-54.

50. Pécora JD, Costa WF, Maia Campos G. A study of the dentinal permeability of the pulp chamber floor of human lower molars with separate roots. Braz Dent J. 1990;1(1):17-24.

51. Pitts NB. Are we ready to move from operative to non-operative/preventive treatment of dental caries in clinical practice?. Caries Res. 2004;38:294-304. 
52. Ramos RP, Chimello DT, Chinelatti MA, Nonaka T, Pécora JD, Palma Dibb RG. Effect of Er:YAG laser on bond strength to dentin of a self-etching primer and two single-bottle adhesive systems. Lasers Surg Med. 2002;31(3):16470 .

53. Ramos AC, Esteves-Oliveira M, Arana-Chavez VE, de Paula Eduardo C. Adhesives bonded to erbium:yttrium-aluminum-garnet laser-irradiated dentin: transmission electron microscopy, scanning electron microscopy and tensile bond strength analyses. Lasers Med Sci. 2010 Mar;25(2):181-9.

54. Raucci-Neto W, Chinelatti MA, Ito IY, Pécora JD, Palma-Dibb RG. Influence of Er:YAG laser frequency on dentin caries removal capacity. Microsc Res Tech. 2010 Jul 9. [Epub ahead of print]

55. Raucci-Neto W, De Castro LM, Corrêa-Afonso AM, Da Silva RS, Pécora JD, Palma-Dibb RG. Assessment of thermal alteration during class $\mathrm{V}$ cavity preparation using the Er:YAG laser. Photomed Laser Surg. 2007 Aug;25(4):281-6.

56. Roth KK-F, Duczynski EW. Ablation of healthy and carious enamel and dentin by erbium:YAG laser irradiation. Proc SPIE.1995;1984:44-51.

57. Shigetani Y, Okamoto A, Abu-Bakr N, Iwaku M. A study of cavity preparation by Er:YAG laser--observation of hard tooth structures by laser scanning microscope and examination of the time necessary to remove caries. Dent Mater J. 2002 Mar;21(1):20-31.

58. Smales RJ; Fang DT. In vitro effectiveness of hand excavation of caries with the ART technique. Atraumatic restorative treatment. Caries Research. 1999;33(6):437-440.

59. Swift EJ Jr, Perdigão J, Heymann HO. Bonding to enamel and dentin: a brief history and state of the art. Quintessence International. 1995;26(2):95-110. 
60. Takamori K, Furukawa H, Morikawa Y, Katayama T, Watanabe S. Basic study on vibrations during tooth preparations caused by high-speed drilling and Er:YAG laser irradiation. Lasers Surg Med. 2003;32(1):25-31.

61. Tao L, Pashely DH, Boyd L. Effect of different types of smear layers on dentin and enamel shear bond strengths. Dent Mater. 1988 Aug;4(4):208-16.

62. Ten Cate JM. Remineralization of caries lesions extending into dentin. J Dent Res. 2001 May;80(5):1407-11.

63. Visuri SR, Gilbert JL, Wright DD, Wigdor HA, Walsh JT Jr. Shear strength of composite bonded to Er:YAG laser-prepared dentin. Journal of Dental Research. 1996;75(1):599-605.

64. Yazici AR, Ozgünaltay G, Dayangaç B. A scanning electron microscopic study of different caries removal techniques on human dentin. Oper Dent. 2002 Jul-Aug;27(4):360-6. 
Anexos 


\section{UNIVERSIDADE DE SÃO PAULO}

Faculdade de Odontologia de Ribeirão Preto

Comitê de Ética em Pesquisa

Of. CEP / 233 / FORP

Ribeirão Preto, 24 de maio de 2010

Ref. processo $n .^{\circ}$ 2009.1.338.58.3 CAAE n. ${ }^{\circ} 0021.0 .138 .000-09$

Senhora Pesquisadora,

A pedido da Profa. Dra. Cláudia Heiena Lovato da Silva, Coordenadora do Comitê de Ética em Pesquisa, desta Faculdade, informamos que o referido Comitê em sua $109^{a}$ Sessão, realizada em 20 de maio de 2010, aprovou o Relatório Parcial do Projeto de Pesquisa: "Avaliação da influência do Er:YAG laser na permeabilidade da dentina após a remoção de cárie".

$\mathrm{Na}$ oportunidade, lembramos da necessidade de entregar na Secretaria do Comitê, com o formulário preenchido pelo pesquisador responsável, o Relatório Final no dia 30 de abril de 2011.

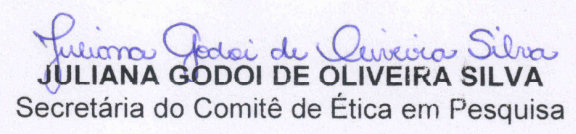

IIma. Sra.

PG. CARMEN VICTORIA TORRES TORO

Departamento de Odontologia Restauradora desta Faculdade 


\section{Submission Confirmation for Journal of Dentistry}

De: ees.jjod.0.eba9b.b801ad12@eesmail.elsevier.com en nombre de Journal of Dentistry (JoD@elsevier.com)

Enviado: lunes, 24 de enero de 2011 05:40:20 p.m.

Para: carvic-chan@hotmail.com

Dear D.D.S. Guenka Palma-Dibb,

Your submission entitled "Influence of Er:YAG laser in removing

demineralized substrate and dentin permeability" has been received by the

Journal of Dentistry.

You will be able to check on the progress of your paper by logging on to Elsevier Editorial System as an author. The URL is http://ees.elsevier.com /jjod/.

Your manuscript will be given a reference number once an Editor has been assigned.

Thank you for submitting your work to this journal.

Kind regards,

Julie Millard

Journal Manager

Journal of Dentistry 